Article

\title{
Investigation of Lateral Confinement, Roller Aspect Ratio and Wear Condition on HPGR Performance Using DEM-MBD-PRM Simulations
}

\author{
Victor Alfonso Rodriguez ${ }^{1}$, Gabriel K. P. Barrios ${ }^{1}$ (D), Gilvandro Bueno ${ }^{2}$ and Luís Marcelo Tavares ${ }^{1, *(D)}$ \\ 1 Department of Metallurgical and Materials Engineering, Universidade Federal do Rio de \\ Janeiro-COPPE/UFRJ, Cx. Postal 68505, Rio de Janeiro CEP 21941-972, Brazil; \\ victoralfonso@metalmat.ufrj.br (V.A.R.); gkpbarrios@metalmat.ufrj.br (G.K.P.B.) \\ 2 Vale S.A., Complexo de Tubarão, Vitória CEP 29090-911, Brazil; gilvandro.bueno@vale.com \\ * Correspondence: tavares@metalmat.ufrj.br; Tel.: +55-2290-1544 (ext. 246)
}

Citation: Rodriguez, V.A.; Barrios, G.K.P.; Bueno, G.; Tavares, L.M. Investigation of Lateral Confinement, Roller Aspect Ratio and Wear Condition on HPGR Performance Using DEM-MBD-PRM Simulations. Minerals 2021, 11, 801. https:// doi.org/10.3390/min11080801

Academic Editor: Thomas Mütze

Received: 18 June 2021

Accepted: 21 July 2021

Published: 23 July 2021

Publisher's Note: MDPI stays neutral with regard to jurisdictional claims in published maps and institutional affiliations.

Copyright: (c) 2021 by the authors. Licensee MDPI, Basel, Switzerland. This article is an open access article distributed under the terms and conditions of the Creative Commons Attribution (CC BY) license (https:/ / creativecommons.org/licenses/by/ $4.0 /)$.

\begin{abstract}
It has been known that the performance of high-pressure grinding rolls (HPGR) varies as a function of the method used to laterally confine the rolls, their diameter/length (aspect) ratio as well as their condition, if new or worn. However, quantifying these effects through direct experimentation in machines with reasonably large dimensions is not straightforward, given the challenge, among others, of guaranteeing that the feed material remains unchanged. The present work couples the discrete element method (DEM) to multibody dynamics (MBD) and a novel particle replacement model (PRM) to simulate the performance of a pilot-scale HPGR grinding pellet feed. It shows that rotating side plates, in particular when fitted with studs, will result in more uniform forces along the bed, which also translates in a more constant product size along the rolls as well as higher throughput. It also shows that the edge effect is not affected by roll length, leading to substantially larger proportional edge regions for high-aspect ratio rolls. On the other hand, the product from the center region of such rolls was found to be finer when pressed at identical specific forces. Finally, rolls were found to have higher throughput, but generate a coarser product when worn following the commonly observed trapezoidal profile. The approach often used in industry to compensate for roller wear is to increase the specific force and roll speed. It has been demonstrated to be effective in maintaining product fineness and throughput, as long as the minimum safety gap is not reached.
\end{abstract}

Keywords: discrete element method; simulation; multibody dynamics; particle replacement; highpressure grinding rolls

\section{Introduction}

Over the last 30 years, high-pressure grinding rolls technology has been evolving in response to different challenges imposed by the mineral processing industry. The HPGR dimensions have been increasing significantly, mainly driven by the proven comminution energy efficiency [1-3] and the high capacity of the equipment [4,5]. Indeed, the first commercial HPGR, installed by the KHD Humboldt Wedag in the Dykerhoff Lengerich cement plant in Wiesbaden Germany, contained rolls measuring $1150 \mathrm{~mm}$ in diameter and $1000 \mathrm{~mm}$ in length, equipped with two $300 \mathrm{~kW}$ motors each [6]. Nowadays the largest machine installed is, apparently, the HRC 3000, manufactured by Metso and commissioned in Freeport Morenci operation, with rolls with $3000 \mathrm{~mm}$ diameter and length of $2000 \mathrm{~mm}$, powered by one $5700 \mathrm{~kW}$ motor each [7].

Besides diameter, the aspect (diameter/length) ratio of the rolls has also been known to be an important factor that affects the performance of the HPGR [5,8]. It is an important design variable and values typically vary from one manufacturer to another. Machines with low-aspect ratio are naturally more expensive but also offer an intrinsically longer wear life for a given application, owing to the more uniform pressure distribution along 
the rolls. On the other side, high-aspect ratio machines have a higher pressure peak in the compression zone, and have been known to generate a finer product from the center of the rolls [5,8]. Indeed, the traditional HPGR manufacturer Polysius, a ThyssenKrupp company, favored a high-aspect ratio design, with large roll diameter and smaller length. An example is the Cyprus Sierrita unit, with $2400 \mathrm{~mm}$ diameter and $1400 \mathrm{~mm}$ length rolls [9], and the Metso HRC design. The other traditional manufacturer, KHD (KHD Humboldt Wedag AG, Cologne, Germany), favored low-aspect ratio HPGRs [10], whereas Köppern (Maschinenfabrik Köppern GmbH and Co KG, Hattingen, Germany) was known to manufacture HPGRs with aspect ratios of nearly one.

The confinement system is another constructive part of the machine that influences its performance $[7,11,12]$. It aims at preventing material bypass, which reduces the pressure drop towards the edge of the rolls. Two types of confinement systems are available. The so-called "cheek plates", used by most HPGR manufacturers, consist of fixed thrust plates positioned on the sides of the rollers [13-15]. The other confinement system, originally proposed by Metso and taken up recently by other manufacturers, consists of rotating side plates or flanges attached to the edge of one of the rolls, confining laterally the opposite roll [7]. Some benefits have been associated with the use of the flanged rolls. One is associated with the fact that it moves with the material once it is through the crushing zone, which means reduced wear [12]. It also enables reaching higher crushing forces at the tire edge, achieving more uniform pressure profiles as a consequence of the improved confinement system [11,16]. Another benefit associated to the flanged roll confinement is its higher throughput [17], as a consequence of the material flow carried on by the flange surface.

The major culprit for lost operating time during HPGR operation is wear of the roller surfaces [5]. In addition, the roller surface of the HPGR directly influences important variables such as product size distribution, nip angle, and, consequently, throughput $[18,19]$. This is related to the grip required to induce movement of the particle bed between rollers. The first HPGRs used in the cement industry were rollers with smooth surfaces. Afterwards, welding was used to protect the surface of the rolls and increase the machine availability, allowing it to be used in size reduction of cement clinker, which is more abrasive than the raw meal [4]. Rollers were originally manufactured in white cast iron rich in chromium (WCI), which is a component of eutectic carbides M7C3 type in a martensitic matrix [18]. Materials then evolved to nickel and cast-iron alloy called Ni-hard (Fe82-Cr9-Ni5-C3), which is characterized by higher fracture toughness, with much higher resilience and durability than the WCI alloy [20]. The greatest challenge for the rolls surface design was posed by the application of the HPGR in size reduction of hard rocks $[9,10,13]$. The introduction of the studded rolls made possible the application of HPGRs in mineral processing in general. The studs, which consist of tungsten carbide cylinders, are attached to the forged steel rolls, leaving some interstices between them, where an autogenous layer of material is formed, which provides protection to the rollers [20].

In order to improve the HPGR performance, several authors attempted to gain insights into the process through experimental tests $[13,18,20-24]$. Unfortunately, the investigation of variables such as lateral confinement system, aspect ratio and wear condition of the rollers on the performance of HPGRs is very difficult experimentally, given the challenge of guaranteeing that the same material is fed to the different machines, among others. The result is the lack of clarity on the effect of these variables on the machine performance, in particular on the axial pressure profile along the rolls. One powerful tool that has been used over the years to study various aspects of HPGR performance is the discrete element method (DEM). DEM is a numerical approach that has been widely accepted as an effective method to deal with engineering problems involving granular and discontinuous media, with important applications in granular flows, rock mechanics and comminution [25]. DEM has already proven to be useful to describe the performance variables as well as the throughput, velocity and pressure profile along the rolls [26-31]. In spite of the relatively 
widespread use of DEM, only a few studies describe particle breakage and account for the dynamics of the movable roll, which is a key part of the equipment.

The present work deals with the application of DEM to study, through simulation, the influence of confinement system, roll aspect ratio and surface wear profile on the performance of a pilot-scale HPGR used in pellet feed grinding. It is based on the description of the floating roll position using the dynamic geometry module (MBD) implemented in the software Altair EDEM ${ }^{\mathrm{TM}}$, originally proposed by Barrios and Tavares [26], and updated using the particle replacement model (PRM) proposed recently by Tavares et al. [32]. The work relies on DEM and PRM parameters, as well as the CAD geometry and operational HPGR conditions obtained from another work by the authors [31], where a detailed validation of the approach has also been carried out on the basis of pilot-scale data. DEM simulations are used to predict key performance variables of the HPGR, besides the axial profiles of mass flowrate, particle velocity and compressive force along the rolls, with a qualitative assessment of the product size distributions.

\section{Materials and Methods}

Discrete element method (DEM) simulations were carried out using the commercial software Altair EDEM version 2020.3. A detailed description of the numerical method can be found elsewhere $[25,33]$. Simulations were run in a computer equipped with $32 \mathrm{~GB}$ in RAM, Intel ${ }^{\circledR}$ Core i7-8700K CPU GHz 3.7. A recently proposed PRM [32] was used, which was implemented as an application programming interface (API) using the Hertz-Mindlin (no-slip) contact model considering a spherical particle replacement [34]. This contact model and particle geometry have the advantage of the ability to track the motion and gross kinetics of a large number of particles with good computational efficiency [25].

\subsection{Materials}

The material and contact parameters used in the present work were calibrated in great detail based on previous bench-scale tests, which included measurement of static and dynamic angle of repose and force-deformation profile in a piston-and-die system [31]. It was recognized that it is not feasible to represent in the DEM simulations the particle size distribution (PSD) of the feed to the pilot-scale HPGR, consisting of pellet feed fines with an $80 \%$ passing size of $234 \mu \mathrm{m}$, representing the feed to a pre-grinding stage. As such, it was proposed to use the arbitrarily coarser (scaled-up) size distribution given in Table 1 in the simulations rather than a single particle size in order to avoid the appearance of crystallization patterns in the material flow, but without attempting to describe quantitatively the fine size distribution fed to the machine. Associated particle contact parameters estimated from the calibration tests are presented in Table 2 [31]. A minimum resolved particle size of $1.16 \mathrm{~mm}\left(D_{\min }\right)$ was used in the simulations (Table 3). Finally, in order to replicate the particle bed response when submitted to compressive stresses in a piston-and-die, the authors selected a value of shear modulus of $2 \times 10^{9} \mathrm{~Pa}$ and DEM particle density of $3520 \mathrm{~kg} / \mathrm{m}^{3}$, with PRM breakage parameters given in Table 3 [31].

Table 1. Simulated particle size distribution.

\begin{tabular}{ccccc}
\hline Particle Size $(\mathbf{m m})$ & $\mathbf{8 . 0}$ & $\mathbf{7 . 2}$ & $\mathbf{6 . 4}$ & $\mathbf{5 . 6}$ \\
\hline Percentage in volume & 40 & 23 & 22 & 15 \\
\hline
\end{tabular}

Table 2. Contact parameters used in the DEM simulations.

\begin{tabular}{cccc}
\hline Contact Type & Coefficient of Restitution & Coefficient of Static Friction & Coefficient of Rolling Friction \\
\hline Ore-Steel & 0.15 & 0.49 & 0.47 \\
Ore-Ore & 0.20 & 0.55 & 0.51 \\
\hline
\end{tabular}


Table 3. Summary of particle breakage parameters used in the DEM simulations.

\begin{tabular}{cccccccccc}
\hline Parameter & $E_{\infty}(\mathrm{J} / \mathbf{k g})$ & $d_{\boldsymbol{o}}(\mathbf{m m})$ & $\boldsymbol{\varphi}$ & $\sigma$ & $\gamma$ & $A$ & $\boldsymbol{b}^{\prime}$ & $D_{\text {min }}(\mathbf{m m})$ & $E_{\text {max }} / E_{50}$ \\
\hline Value & 500 & 75 & 0.35 & 0.8 & 5.0 & 68 & 0.03 & 1.2 & 4 \\
\hline
\end{tabular}

\subsection{DEM Equipment Setup}

A two-way coupled model based on multi-body dynamics (MBD) and discrete element method (DEM) was used to calculate the dynamics of the floating roll. EDEM 2020.3 has important advances incorporating motion controllers that allow objects to react to particlegeometry forces. With this tool, it was possible to describe the rotation and the translation dynamics in the floating roll, as proposed originally by Edwards et al. [35]. The scheme consists of two motion controllers, one as a force in the longitudinal direction " $\mathrm{x}$ ", obtained from the product of specific force $\left(\mathrm{N} / \mathrm{mm}^{2}\right)$ and the projected area $D \times L\left(\mathrm{~mm}^{2}\right)$, and the other control as a torque for the rotating movement. A rotating movement with a selected fixed angular velocity and with no motion controller was used in the case of the fixed roll. Being a one-dimensional model, it does not allow for skewing of the rolls. The rolls movement starts only when DEM particles fill the hopper from a particle factory located above the rolls. From this point on in the simulation, new particles were added continuously. Simulations were run until stability was reached for the HPGR performance variables, which typically occurred after about $2 \mathrm{~s}$ of operation.

\subsection{Base Case}

A pilot-scale Roller Press RPR 03.6-100/32 manufactured by KHD Humboldt Wedag AG was selected for the base case. The rolls are $1000 \mathrm{~mm}$ diameter and $320 \mathrm{~mm}$ long, while the HPGR operates with parameters presented in Table 4. Experimental data were available from two tests conducted under these conditions.

Table 4. Parameter of the base case condition simulated.

\begin{tabular}{cccc}
\hline Variable & Symbol & Units & Value \\
\hline Confinement system & - & - & Cheek plate \\
Rolls diameter & $D$ & $\mathrm{~mm}$ & 1000 \\
Rolls length & $L$ & $\mathrm{~mm}$ & 320 \\
Rolls peripheral velocity & $U$ & $\mathrm{~m} / \mathrm{s}$ & 0.5 \\
Studs diameter & $d_{s t}$ & $\mathrm{~mm}$ & 15.9 \\
Studs protruding height & $I_{S t}$ & $\mathrm{~mm}$ & 5.0 \\
Autogenous area fraction & - & - & 0.65 \\
Zero gap & $x_{0}$ & $\mathrm{~mm}$ & 1.0 \\
Specific force & $S F$ & $\mathrm{~N} / \mathrm{mm}^{2}$ & $2.5 / 3.5$ \\
\hline
\end{tabular}

* Force on the rolls divided by $D \times L$.

\subsection{Confinement Systems}

The confinement system seals the lateral outlets to prevent material bypass, which is responsible for a drop in pressure towards the edge of the rolls. Two types of confinement systems are simulated. The one used in the base case relies on cheek plates, which consist of fixed thrust plates positioned on the sides of the rollers (Figure 1a). The other is the rotating side plate or flanges, which consists of rims with diameter larger than the rolls that are attached to both edges of the fixed roller. In the present work two types of flanges were simulated: The first one with smooth surfaces (Figure 1b), and the other with studs measuring $15.9 \mathrm{~mm}$ in diameter and protruding $5 \mathrm{~mm}$ from the roll surface, introduced to improve the grip of the material between the rolls (Figure 1c). In both cases, flanges have $50 \mathrm{~mm}$ of height from the rollers. 


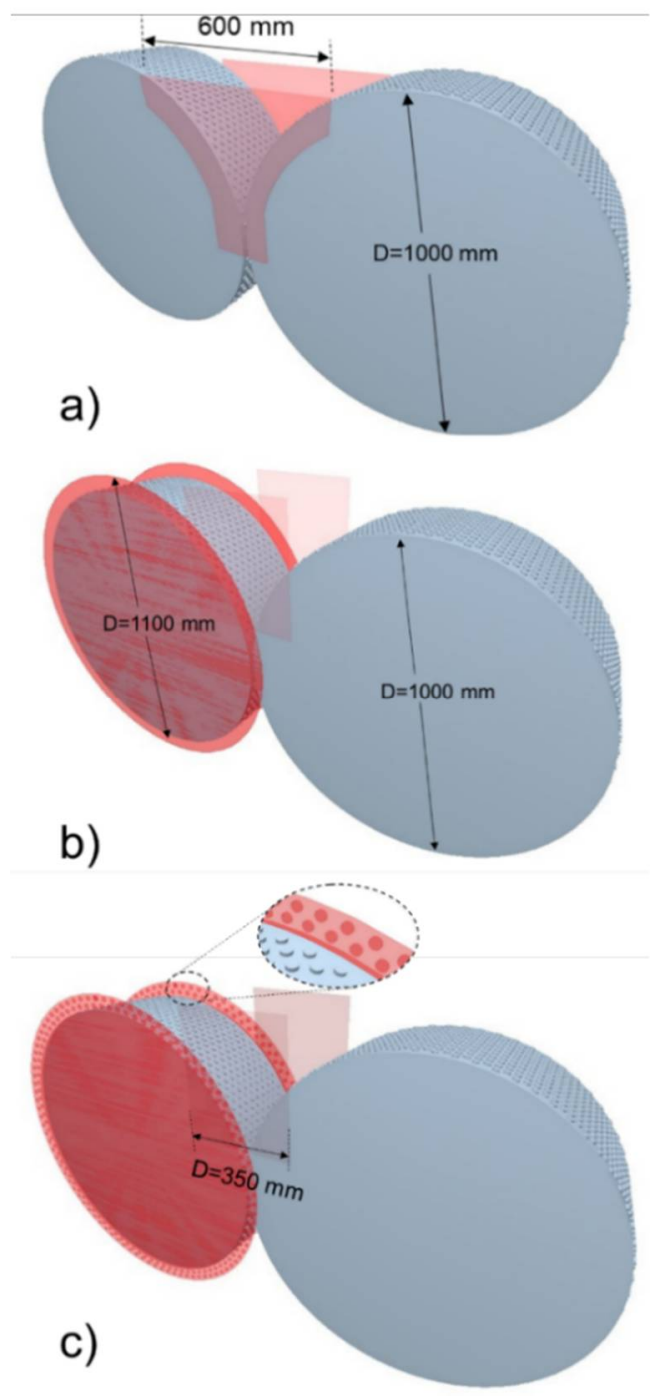

Figure 1. CAD images of pilot HPGRs with different confinement systems: (a) Cheek plates, (b) smooth flanges and fixed side plates and (c) studded flanges and fixed side plates.

\subsection{Aspect Ratio}

In order to analyze the influence of the diameter/length (D/L) or aspect ratio of the rolls, DEM simulations with different ratios were performed. Besides the base case with D/L ratio of 3.13 (Table 4), HPGRs with two additional ratios were simulated. One emulated the ratio of 1.22 used in an industrial HPGR manufactured by Thyssenkrupp Polysius [36], resulting in a length of $820 \mathrm{~mm}$, whereas the other corresponded to a rolls length of $1200 \mathrm{~mm}$, and an aspect ratio of 0.83 . In all these cases the remaining design and operating parameters, including the rolls diameter $(1000 \mathrm{~mm})$, were maintained equal to those of the base case (Table 4).

\subsection{Worn Rollers}

Besides the patterns found in the literature $[12,20]$, wear patterns were obtained from measurements in an industrial HPGR. A metal strip with designed holes was used. The procedure consisted of placing the strip in front of the axial surface of the roll. A digital caliper was used to measure the distance from the strip to the roll surface in each designed hole. Afterwards, the measured pattern was smoothed and input in detail in a CAD representation of the worn rolls for the DEM simulations. In these simulations, the roll length of $820 \mathrm{~mm}$ was considered, since it better approaches the aspect ratio of the industrial HPGR from which data were collected. 
Two wear patterns were considered in the simulations. The first is a parabolic pattern with greater wear right on the center of the rolls (Figure 2). While a maximum wear depth of $5 \mathrm{~mm}$ was observed experimentally, a pattern corresponding to the mid-life condition with $2.5 \mathrm{~mm}$ depth was designed and simulated. The second pattern has an approximately trapezoidal or "bathtub" shape, with equally intense wear in the center of the rolls, with very modest wear in the edge region (Figure 2). In this case, the wear profiles corresponding to both the maximum wear depth and the mid-life condition were designed and simulated.

Finally, in order to mimic the industrial practice used to compensate wear in HPGR operations, the compressive force has been increased in an attempt to adjust the gap and increase the specific energy in the operation, while the roll velocity was increased to maintain throughput approximately constant. As such, a simulation with the trapezoidal wear pattern with $2.5 \mathrm{~mm}$ in depth (mid-life) was performed, increasing the specific force to $4.0 \mathrm{~N} / \mathrm{mm}^{2}$ and the roll velocity to $0.6 \mathrm{~m} / \mathrm{s}$.

Parabolic surface wear profile

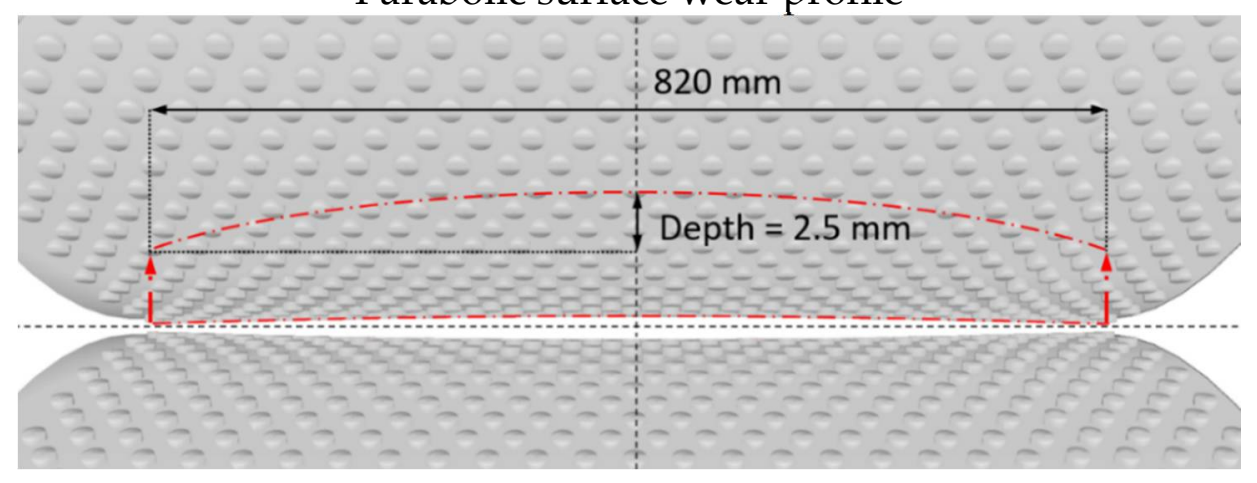

Trapezoidal surface wear profile

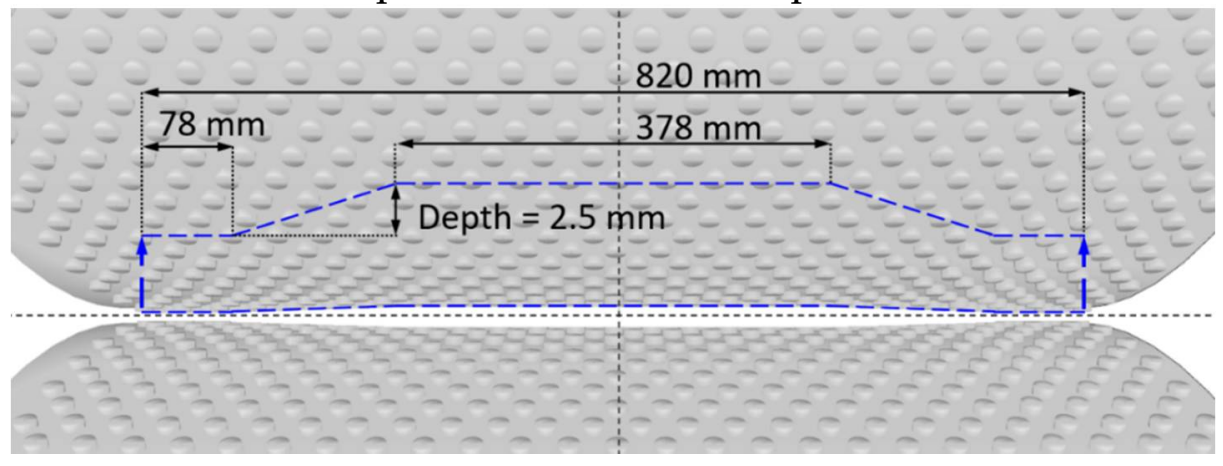

Figure 2. Wear profiles of the simulated rollers.

\subsection{Measurement of Key Variables}

The key variables taken into consideration to assess variations in performance owing to the changes in design variables were throughput, power and product fineness. Besides those, pressure, mass flowrate and product size along the axial roll profile were also analyzed in the simulations. In order to measure the total throughput, two cylindrical mass flow sensors were positioned in the center, $250 \mathrm{~mm}$ underneath the gap between the rolls. One of the flow sensors was introduced with a diameter equal to the length of the rolls to measure the mass flow coming directly from the rolls, while an additional mass flow sensor measuring 1.25 times the roll length was introduced to measure the total mass flow (Figure 3). The difference between them allows estimating the flowrate of material that escaped from the clearance between the rolls and the lateral confinement, also called bypass. 


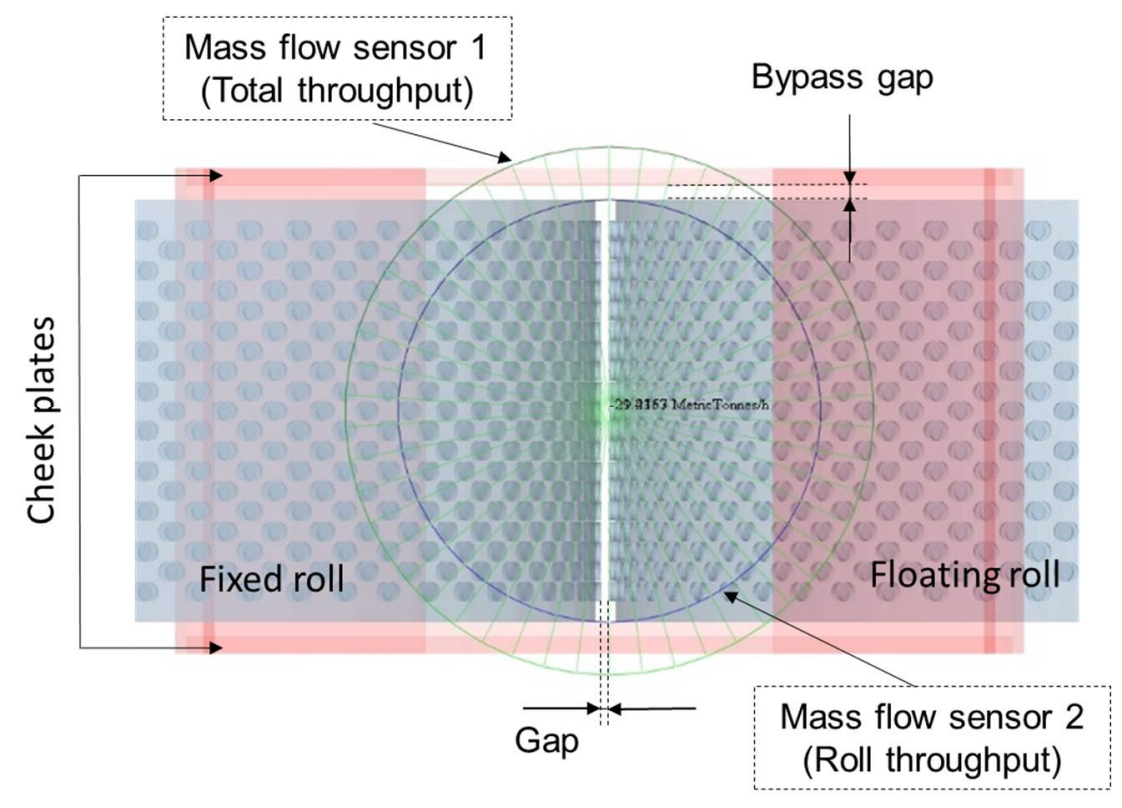

Figure 3. Bottom view of the simulated pilot-scale HPGR with cheek plates representing the mass flow sensors used to measure the total and roll throughput.

The axial response along the rolls of three key variables was measured when the HGPR was operating under steady-state conditions. First, the force profile on the bed was obtained from a square grid bin geometry composed of 60 elements that started from the roll gap to $100 \mathrm{~mm}$ above it. The mass flowrate profile was also measured. In this case, the same grid bin was also used but positioned underneath the rolls gap, with the aim of extracting the mean velocity, mass and product PSD for each bin (Figure 4). The product PSD profile along the rolls was obtained at a post-processing stage using the approach proposed by Tavares et al. [32]. In order to process all the profiles (i.e., force, mass flowrate and product PSD) in simulations with different roll lengths (aspect ratios), the number of bins was changed so that the length and width of each bin were maintained equal to 100 and $5.7 \mathrm{~mm}$, respectively, as can be observed in Figure 4.

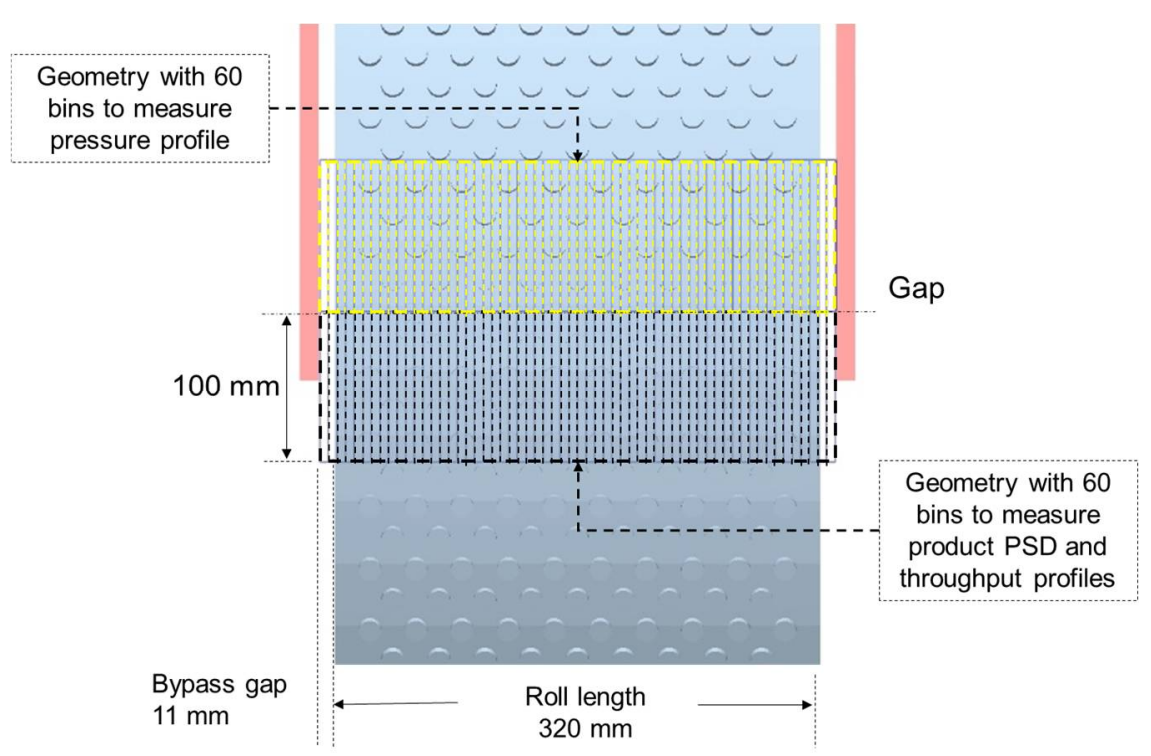

Figure 4. Top view of the pilot-scale HPGR showing the position of the 60 bins, each one with $100 \mathrm{~mm} \times 5.7 \mathrm{~mm}$, to measure key variables along the rolls. 
The specific throughput $\left(\mathrm{ts} / \mathrm{hm}^{3}\right)$ was also then calculated by [5]:

$$
\dot{m}=\frac{M}{D L U},
$$

where $M$ is the throughput, and $D, L$ and $U$ were defined in Table 4 .

The total force on the floating roll was extracted to calculate the specific force, whereas the center of mass position of the floating roll was used to calculate the operating gap, which was estimated from the top of the studs. In the case of worn rollers, it was estimated considering the top of the studs located on the edge of the rolls. The torque on the rolls served as the basis to calculate the power consumption, after being multiplied by the rotation frequency of the rollers.

\subsection{Bypass Gap}

Whereas the working gap is the result of the interaction between the calibrated material response and the hydraulic roll system, the bypass gap (Figure 3) corresponds to the clearance between the confinement system and the rolls, which results in material ejection from the edge of the rolls. This variable affects the HPGR performance significantly and must be taken into account in the simulations [30]. This effect is particularly relevant in the present case, given the fine size and high moisture content of the feed, being likely less significant in most applications of HPGRs. The challenge is associated to the fact that particles in the feed to the HPGR are significantly finer than those simulated (Table 1), so that an adjustment of the bypass gap in the simulations is needed in order to reproduce the experiments. The pilot scale HPGR (RPR) test operating at a specific force of $2.5 \mathrm{~N} / \mathrm{mm}^{2}$ and roll velocity of $0.5 \mathrm{~m} / \mathrm{s}$ was selected to assess this variable. Besides comparing the experimental and simulated performance variables, the bypass flowrate estimated using the empirical model proposed by Campos et al. [22] was taken into consideration in selecting the bypass gap $\left(x_{b p}\right)$ to be used in the pilot-scale HPGR simulations.

Results of sensitivity analyzes of the simulations to the bypass gap are summarized in Table 5 . In the case of the bypass gap of $6 \mathrm{~mm}$, an excessive low value of bypass mass flowrate was observed, since particles in the feed with sizes above this value become unable to pass through this clearance, whereas for the bypass gap of $15 \mathrm{~mm}$ this proportion was excessive. Since the value of bypass gap that best matched the working gap and the bypass material flow predicted by Campos et al. [22], estimated as $28 \%$ [22], was $11 \mathrm{~mm}$, this was selected in all remaining simulations. One exception is a simulation performed with smooth flanges, where a bypass gap of $6 \mathrm{~mm}$ was selected in order to allow a more direct comparison with the simulation with studded flanges, since the net value of bypass clearance of the former would be reduced to approximately this value given the protruding height of the studs $(5 \mathrm{~mm})$.

Table 5. Summary of the results of DEM simulations of pilot-scale HPGR with cheek plates operating with $2.5 \mathrm{~N} / \mathrm{mm}^{2}$, roll velocity of $0.5 \mathrm{~m} / \mathrm{s}$, top particle size of $8 \mathrm{~mm}$ and for different bypass gaps.

\begin{tabular}{cccc}
\hline \multirow{2}{*}{ Bypass Gap $(\mathbf{m m})$} & \multirow{2}{*}{ Working Gap $\mathbf{( m m )}$} & \multicolumn{2}{c}{ Throughput } \\
\cline { 3 - 4 } & & Total (t/h) & Bypass (\%) \\
\hline Experiment & 7.5 & 26.7 & $27.8^{*}$ \\
6 & 6.4 & 27.5 & 14.6 \\
11 & 6.8 & 32.2 & 31.3 \\
15 & 8.5 & 48.2 & 51.4 \\
\hline
\end{tabular}

* Estimated using the model by Campos et al. [22]. 


\section{Results and Discussion}

\subsection{Confinement Systems}

An image of a DEM simulation is presented in Figure 5, where the particles fed are replaced by finer particles as they experience progressively higher pressures approaching the gap between the rolls. It shows that a measurable amount of material is able to escape from the clearance between the edge of the rolls and the cheek plates (bypass), which is an effect that has been particularly observed during pressing of iron ore pellet feed, owing to its high moisture content and fine size [22,37].

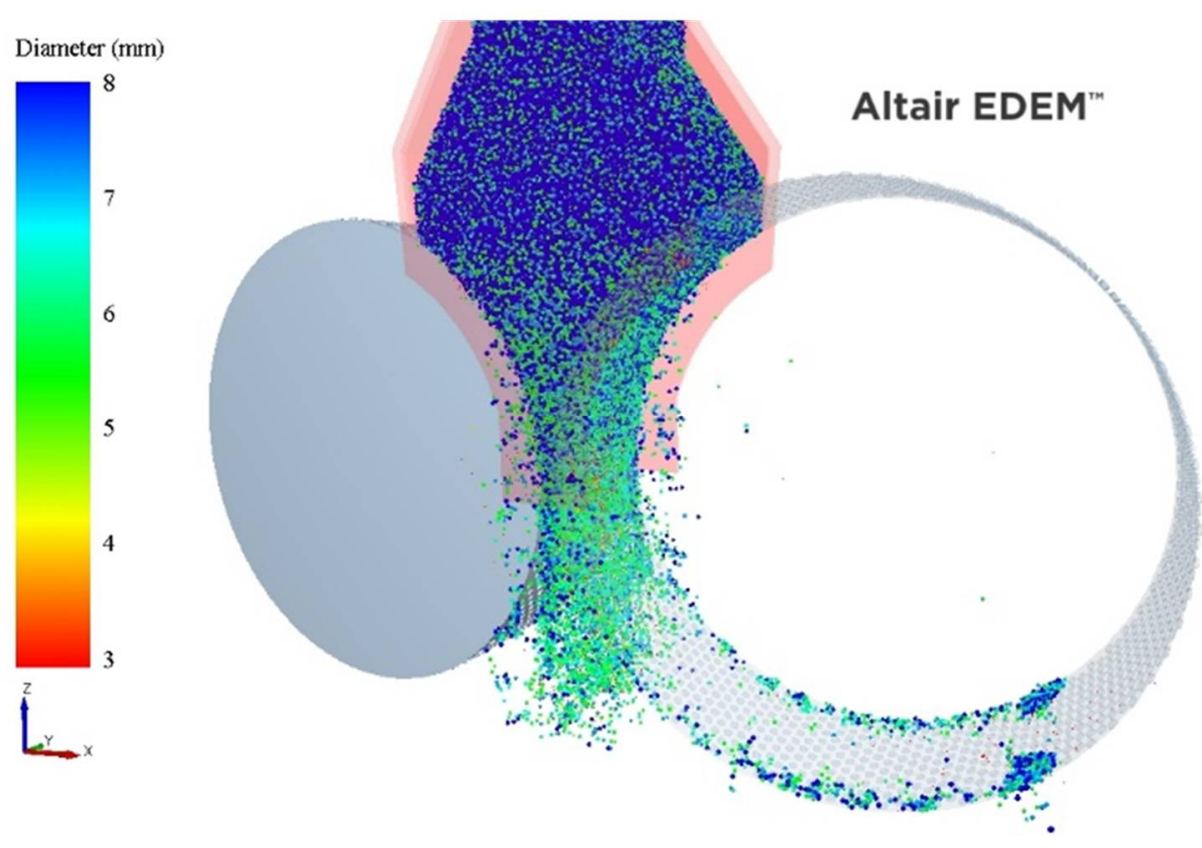

Figure 5. 3D rendered DEM simulation image of the pilot-scale HPGR with cheek plates and particles colored by size. HPGR with an aspect ratio of 3.13, operating with specific force of $3.5 \mathrm{~N} / \mathrm{mm}^{2}$, rolls velocity of $0.5 \mathrm{~m} / \mathrm{s}$ and bypass gap of $11 \mathrm{~mm}$.

A summary of the DEM simulations varying the confinement system can be examined in Table 6. At first, the base case simulation, conducted using cheek plates, was compared to the experimental results. It shows reasonably good agreement between measured and predicted throughput and power. A more detailed validation of the simulation approach, shown in another publication [31], demonstrates that average deviations between measured and predicted throughput and power were $13 \%$ for a total of 13 tests. The product fineness represented by the percentage passing the $45 \mu \mathrm{m}$ sieve; however, is underestimated by the simulations. A more detailed comparison is given in Figure 6, where the feed and product sizes are compared. As such, predictions of product size should be interpreted only qualitatively in the present work, since the simulated feed size distribution (Table 1) needed to be over an order of magnitude coarser than the actual size distribution fed to the HPGR. As informed in Table 3, the minimum size of resolved particles in the DEM simulation was $1.2 \mathrm{~mm}$, so that all particles finer than this size were not resolved in the simulation and were a result of the application of the post-processing approach proposed by Tavares et al. [32]. 
Table 6. Effect of the confinement system on the HPGR performance. Simulations performed with rolls with aspect ratio of 3.13 , specific force of $3.5 \mathrm{~N} / \mathrm{mm}^{2}$, roll velocity of $0.5 \mathrm{~m} / \mathrm{s}$ and bypass gap of $11 \mathrm{~mm}$.

\begin{tabular}{|c|c|c|c|c|c|c|c|c|}
\hline \multirow{2}{*}{$\begin{array}{l}\text { Confinement } \\
\text { System }\end{array}$} & \multirow{2}{*}{$\begin{array}{l}\text { Working } \\
\text { Gap (mm) }\end{array}$} & \multicolumn{3}{|c|}{ Throughput (t/h) } & \multirow{2}{*}{$\begin{array}{l}\text { Specific Throughput } \\
\left(\mathrm{ts} / \mathrm{hm}^{3}\right)\end{array}$} & \multirow{2}{*}{$\begin{array}{c}\text { Power } \\
(\mathrm{kW})\end{array}$} & \multirow{2}{*}{$\begin{array}{c}\text { Ecs } \\
(\mathbf{k W h} / \mathrm{t})\end{array}$} & \multirow{2}{*}{$\begin{array}{c}\text { Product } \\
-45 \mu \mathrm{m}(\%)\end{array}$} \\
\hline & & Rolls & Bypass & Total & & & & \\
\hline Cheek plate (Expt.) & 7.4 & - & - & 26.8 & 167.5 & 66.1 & 2.47 & 52.0 \\
\hline Cheek plate & 5.5 & 21.2 & 9.7 & 30.9 & 193.1 & 62.4 & 2.02 & 20.9 \\
\hline Smooth flanges & 6.3 & 27.4 & 9.3 & 36.7 & 229.4 & 73.2 & 2.00 & 21.4 \\
\hline Studded flanges & 11.6 & 33.0 & 6.6 & 39.6 & 247.5 & 71.8 & 1.81 & 19.1 \\
\hline Smooth flanges * & 9.6 & 28.6 & 3.5 & 32.1 & 200.5 & 76.4 & 2.38 & 22.5 \\
\hline
\end{tabular}

* Bypass gap of $6 \mathrm{~mm}$.

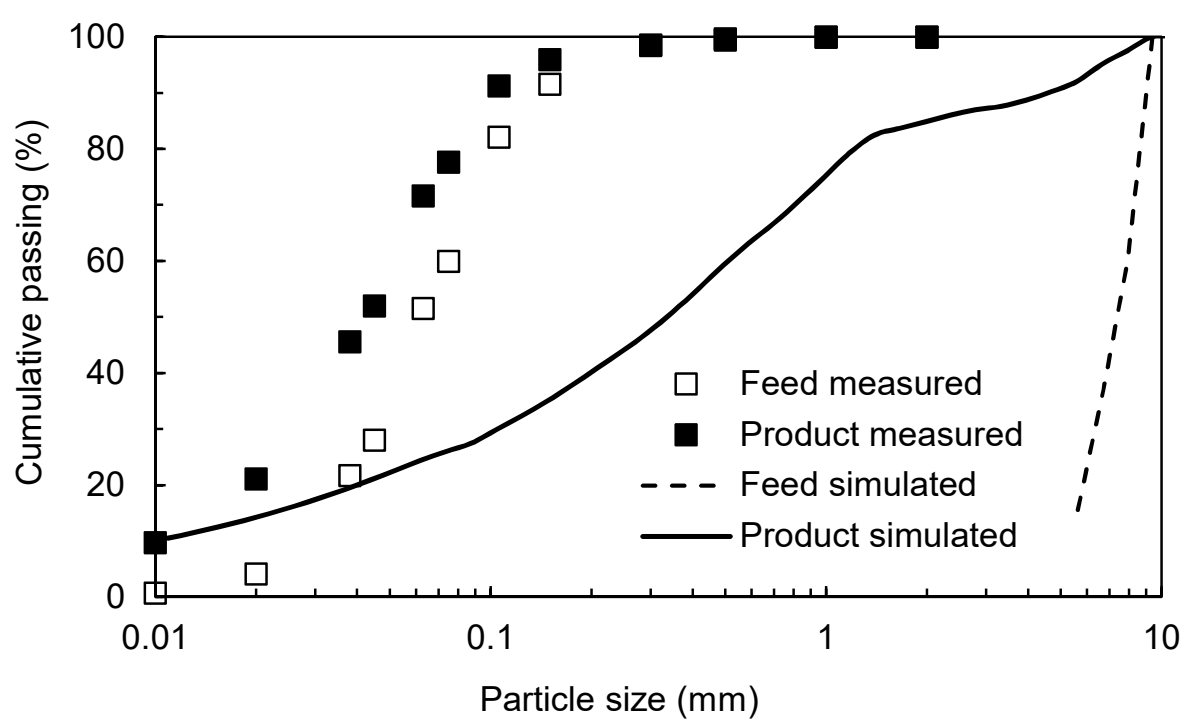

Figure 6. Comparison of measured and predicted feed and product size distributions from a pilotscale HPGR with cheek plates. HPGR with an aspect ratio of 3.13, operating with specific force of $3.5 \mathrm{~N} / \mathrm{mm}^{2}$ and rolls velocity of $0.5 \mathrm{~m} / \mathrm{s}$.

Throughput and power for both simulations with flanged rolls were larger than those with cheek plates, evidencing the ability of the flanges to assist in transporting the material between the rolls (Table 6). The flowrate of material ejected through the clearance between the rolls and the confinement system (bypass) is similar when either cheek plates or smooth flanges are simulated $(9.5 \pm 0.2 \mathrm{t} / \mathrm{h})$, while it is reduced in the case of the flanges with studs $(6.6 \mathrm{t} / \mathrm{h})$ and also with reduced clearance $(3.5 \mathrm{t} / \mathrm{h})$ (Table 6$)$. The action of the studs in the flanges in nipping the particles becomes more evident in the throughputs from the center and edge regions of the rolls, which were $50 \%$ and $17 \%$ higher when compared to simulations with cheek plates and smooth flanges, respectively (Table 6). The net result was an increase of $19 \%$ in throughput when studded flanges were used, which is identical to the increase observed experimentally by Sönmez et al. [12]. As another consequence of the use of studded flanges, the power increased $17 \%$ in comparison to simulations with cheek plates, owing to the higher torque demanded to transport the material (Table 6). However, this also resulted in an increase in the mean working gap in comparison to the simulation with cheek plates, owing to the increase in interaction between the particle bed and the floating roll. Further, a significant reduction in energy consumption between cheek plates and smooth flanges was not observed. Indeed, studded flanges presented a reduction of $10 \%$, which is also comparable to the $13.5 \%$ reduction estimated by Sönmez et al. [12]. The net effect of these results is that product fineness is higher for the simulations in which smooth flanges were used in comparison to that with the cheek plates, whereas a coarser product was predicted when studded flanges were used (Table 6). Further, simulation results with flanges maintaining the same $(6 \mathrm{~mm})$ distance between the roll and either the 
smooth flanges and the roll and the top of the studs are also compared in Table 6 . These demonstrated that studded flanges also allowed reaching higher throughputs both between the rolls and through the bypass clearance. Further, power, specific energy consumption and, as a consequence, fineness of the product was also higher when the bypass clearance was reduced to $6 \mathrm{~mm}$ in comparison to the studded flanges.

In order to allow a more in-depth understanding of how the mass is transported along the rolls, the total mass and the mean particle velocity were used to estimate the throughput profile (Figure 7), as described in Section 2.7. The zero position in the x-axis of the figure represents the center of the rolls in the y-axis (Figure 7), while the dotted lines identify the projection of the length of the rolls. The throughput pattern observed showed that higher solids flowrates are found in the bypass zone, due to free-falling material, with a reduction observed in the edge of the rolls, with a slight drop in the central portion of the rolls. The figure also shows similar throughput profiles for simulations of HPGRs with cheek plates and smooth flanges.

Regarding the simulations with studded flanges and flanges with bypass gap of $6 \mathrm{~mm}$, both show the same throughput profile, where the mass flow from the center of the rolls is similar, although marginally higher, to that reached using the other confinement systems (smooth flanges and cheek plates). Nevertheless, important differences appear in mass flow from the edge of the rolls as well as from the bypass gap. Indeed, Figure 7 shows that the use of studded flanges is responsible for more uniform discharge of the material between the rolls, which translates in the higher overall throughput of the machine when compared to cheek plates, as well as with smooth flanges, as observed in Table 6.

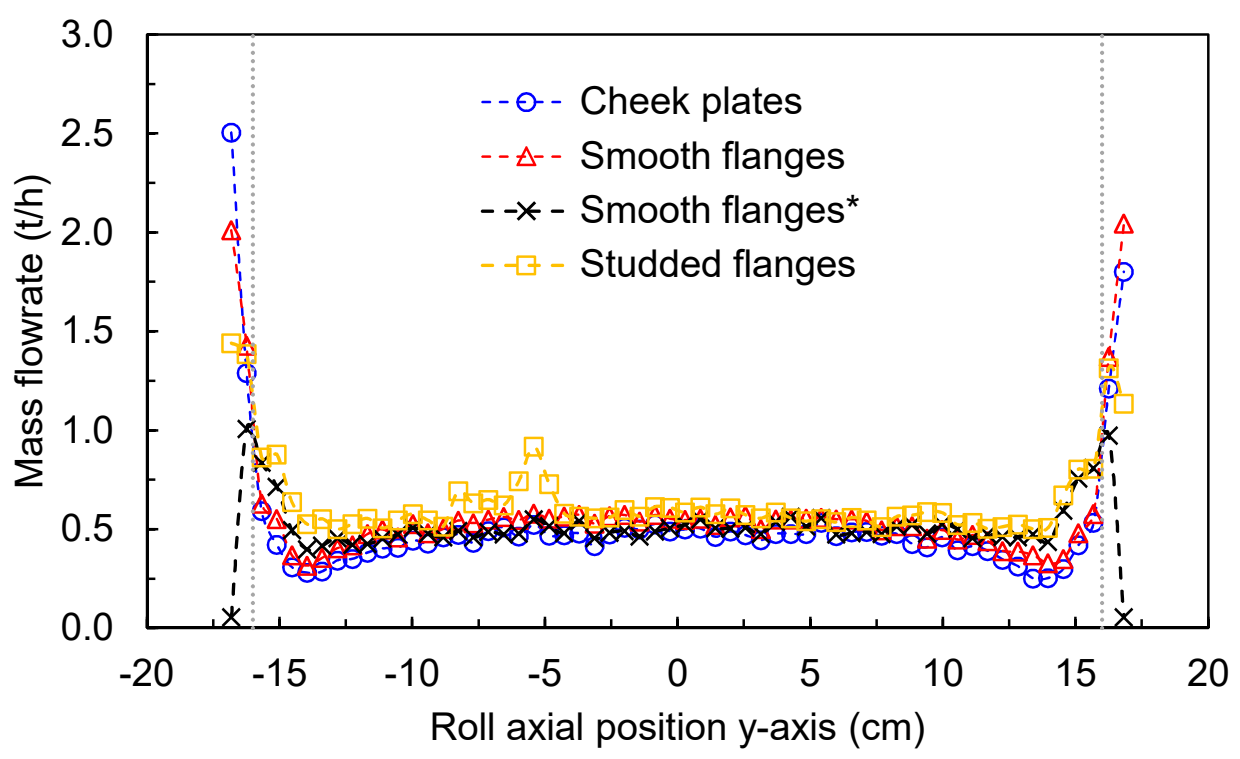

Figure 7. Average axial mass flowrate profiles along the rolls with different confinement systems, with an aspect ratio of 3.13 , operating with a specific force of $3.5 \mathrm{~N} / \mathrm{mm}^{2}$, rolls velocity of $0.5 \mathrm{~m} / \mathrm{s}$ and bypass gap of $11 \mathrm{~mm}$. Vertical dotted lines identify the edge of the rolls. * Flanges with reduced bypass gap $(6 \mathrm{~mm})$.

Besides throughput, the force profile on the particle bed in the gap region is another useful information that can be obtained from DEM simulations. The comparison for the confinement systems simulated is shown in Figure 8. The simulation using cheek plates presents the approximately parabolic pressure profile with pronounced edge effect and maximum pressure in the center of the rolls. This pattern is assumed in some phenomenological models of the HPGR [37-39] and has been already observed in DEM simulations in previous studies $[26,31,40]$. When smooth flanges are used, even reducing the bypass to $6 \mathrm{~mm}$, there is an increase in the magnitude of forces along the rolls, although the drop towards the edge of the rolls still remains evident. Finally, Figure 8 also presents 
the compressive force profile of a simulation with studded flanges. This configuration also shows a reduction in the magnitude of forces acting on the bed towards the edge of the rolls, but not as significant. In the center of the rolls, a mean compressive force of $252 \pm 21 \mathrm{kN}$ is observed, while on the edge the mean compressive force is reduced to $167 \pm 4 \mathrm{kN}$, representing a reduction of only $33 \%$.

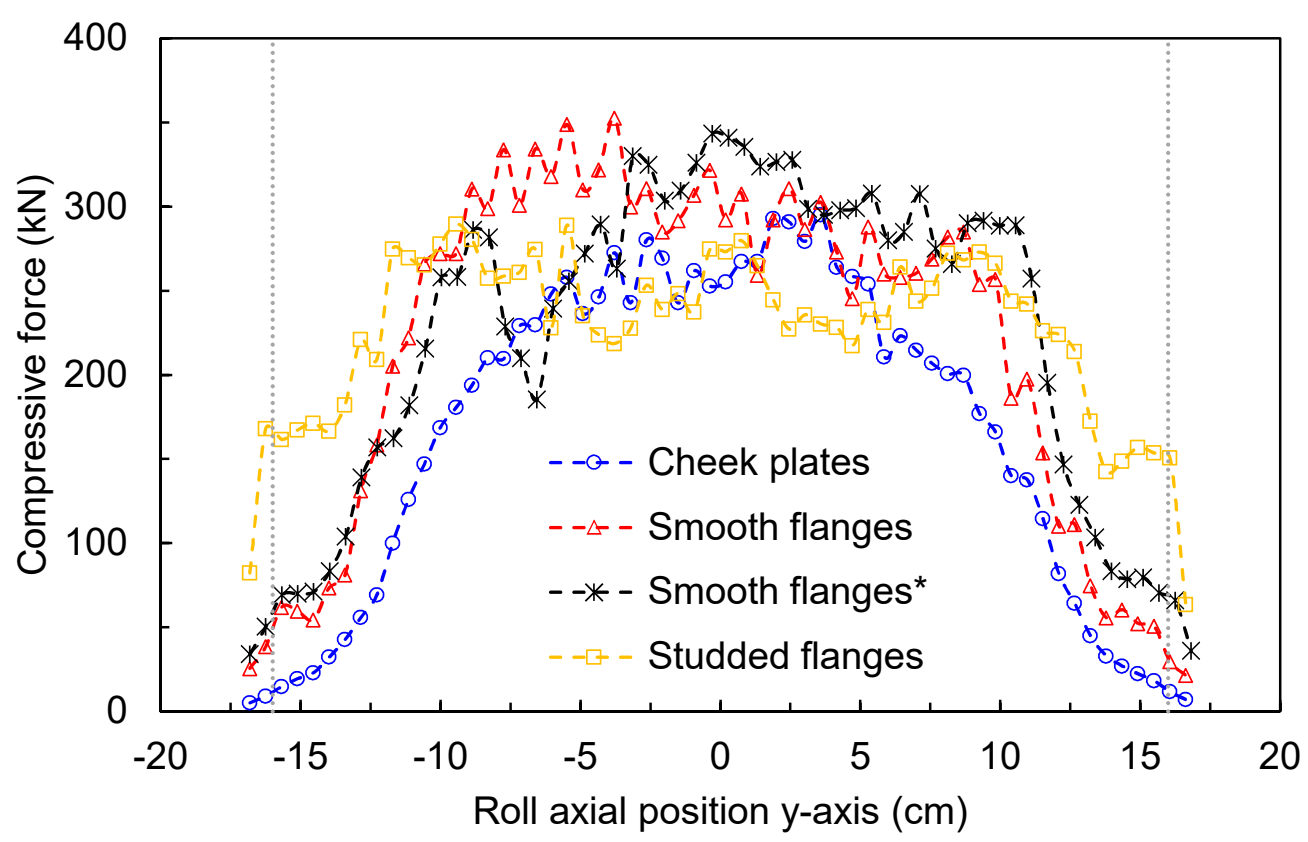

Figure 8. Axial compressive force profiles along the rolls for the HPGRs in the gap region, with different confinement systems with an aspect ratio of 3.13, operating with a specific force of $3.5 \mathrm{~N} / \mathrm{mm}^{2}$ and rolls speeds of $0.5 \mathrm{~m} / \mathrm{s}$. Vertical dotted lines identify the edge of the rolls. * Flanges with reduced bypass gap $(6 \mathrm{~mm})$.

The compressive force profile along the rolls, shown in Figure 8, is typically associated with a variation of the fineness of the product along the axes of the rolls. Such coarsening of the product from the edge region can be responsible for either a wider size distribution of the product in open-circuit operation or an increase in circulating load in closed-circuit operation $[11,12,15]$. In the present work, the Tavares PRM allows to investigate qualitatively the effect of this axial pressure variation on the product size. The results of the product fineness are presented in Figure 9. As expected, the product size distributions from the edge region of the HPGR with the cheek plates are significantly coarser when compared to those with flanges. The smaller bypass clearance $(6 \mathrm{~mm})$ in the simulation with smooth flanges showed the finest particle size in the material ejected from the rolls. Although, in the case of the flanges with studs, the generation of fines was lower in the center zone of the rolls, it demonstrates the more homogenous product discharged along the rolls length. 


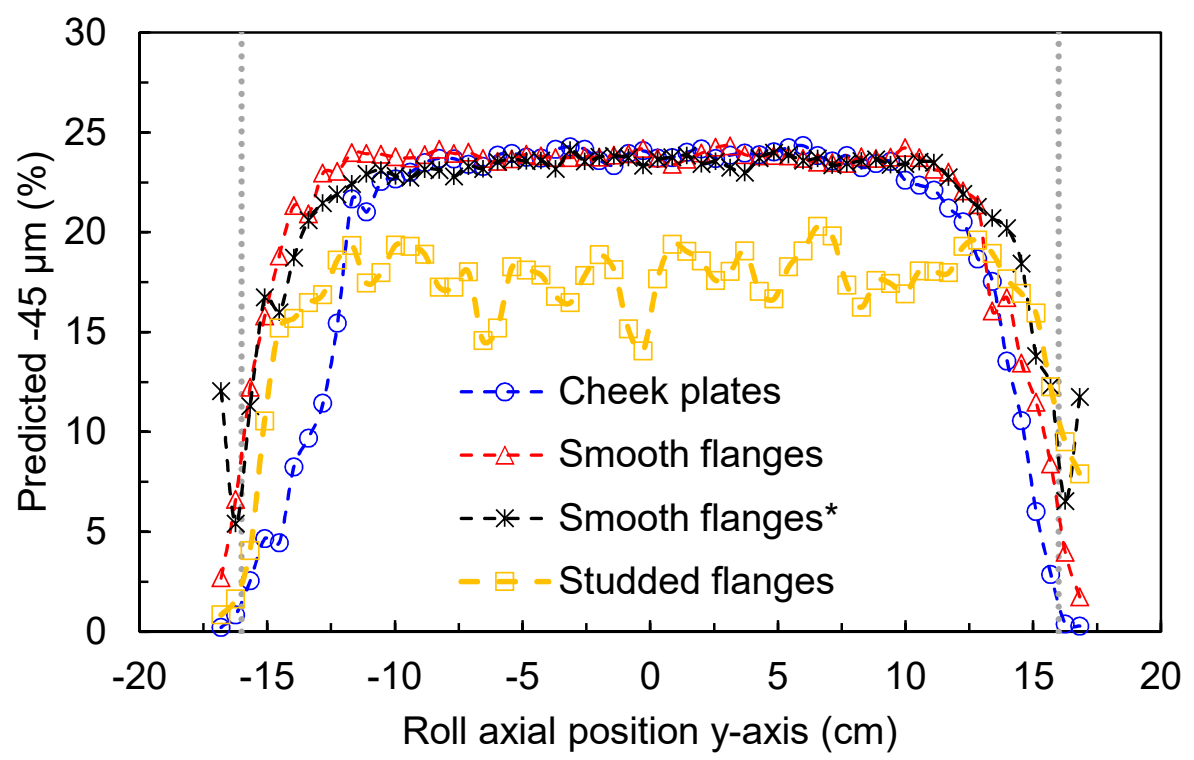

Figure 9. Predicted percentage passing the $45 \mu \mathrm{m}$ sieve in the product along the rolls with different confinement systems for rolls with aspect ratio of 3.13, operating with a specific force of $3.5 \mathrm{~N} / \mathrm{mm}^{2}$, rolls speed of $0.5 \mathrm{~m} / \mathrm{s}$ and bypass gap of $11 \mathrm{~mm}$. * Flanges with reduced bypass gap $(6 \mathrm{~mm})$.

\subsection{HPGR Aspect Ratio}

Table 7 summarizes the results of DEM simulations varying the aspect ratio. The HPGR with the higher aspect ratio presented the smallest working gap in the simulations, while those with 1.22 and 0.83 ratios presented relatively similar values. Not surprisingly, as the aspect ratio decreased there was an increase in both throughput and power, given their proportional variation to the rolls length [5]. Indeed, the result were specific throughputs that varied in a relatively narrow range, with values slightly higher for the HPGR with the lowest aspect ratio. In order to make results more comparable, the specific energy consumption (Ecs) was also reported. A slight difference could be observed, where the specific energy consumption with the aspect ratios of 1.22 and 3.13 were reduced $8.0 \%$ and $5.2 \%$, respectively, when compared to that of the HPGR with the lowest $(0.83)$ aspect ratio. In addition, Table 7 shows that the product fineness of the HPGR increased with the aspect ratio, being highest for the 3.13 aspect ratio.

Table 7. Effect of aspect ratio on the performance of HPGRs with cheek plates. Simulations performed with a specific force of $3.5 \mathrm{~N} / \mathrm{mm}^{2}$, roll velocity of $0.5 \mathrm{~m} / \mathrm{s}$ and bypass gap of $11 \mathrm{~mm}$.

\begin{tabular}{|c|c|c|c|c|c|c|c|c|}
\hline \multirow{2}{*}{ Aspect Ratio } & \multirow{2}{*}{$\begin{array}{l}\text { Working Gap } \\
(\mathrm{mm})\end{array}$} & \multicolumn{3}{|c|}{ Throughput (t/h) } & \multirow{2}{*}{$\begin{array}{l}\text { Specific Throughput } \\
\left(\mathrm{ts} / \mathrm{hm}^{3}\right)\end{array}$} & \multirow{2}{*}{$\begin{array}{c}\text { Power } \\
(\mathbf{k W})\end{array}$} & \multirow{2}{*}{$\begin{array}{c}\text { Ecs } \\
(\mathbf{k W h} / \mathrm{t})\end{array}$} & \multirow{2}{*}{$\begin{array}{c}\text { Product } \\
-45 \mu \mathrm{m}(\%)\end{array}$} \\
\hline & & Rolls & Bypass & Total & & & & \\
\hline 0.83 & 11.8 & 108.4 & 12.6 & 121.0 & 201.7 & 257.6 & 2.13 & 17.2 \\
\hline 1.22 & 11.7 & 66.7 & 11.0 & 77.3 & 188.5 & 151.6 & 1.96 & 17.5 \\
\hline 3.13 & 5.5 & 21.2 & 9.7 & 30.9 & 193.1 & 62.4 & 2.02 & 20.1 \\
\hline
\end{tabular}

Table 7 also discriminates the mass flow passing between the roll center and edge zones from the material ejected from the bypass region. Both the rolls center and edge, as well as bypass throughput, increase as the aspect ratio decreases, although only modestly in the case of the bypass throughput. In Figure 10 the axial mass flowrates along the rolls are presented. The higher ratio shows more material passing through the center of the rolls with a sudden drop near the edge of the rolls until the bypass zone, where a significant increase could be observed due to the free-falling material. For the lower aspect ratios (0.83 and 1.22), a more constant mass flowrate in the center portion of the rolls is evident. Although not as abrupt as that observed for the 3.13 ratio, a reduction of mass flowrate also appears towards the edge of the rolls. 


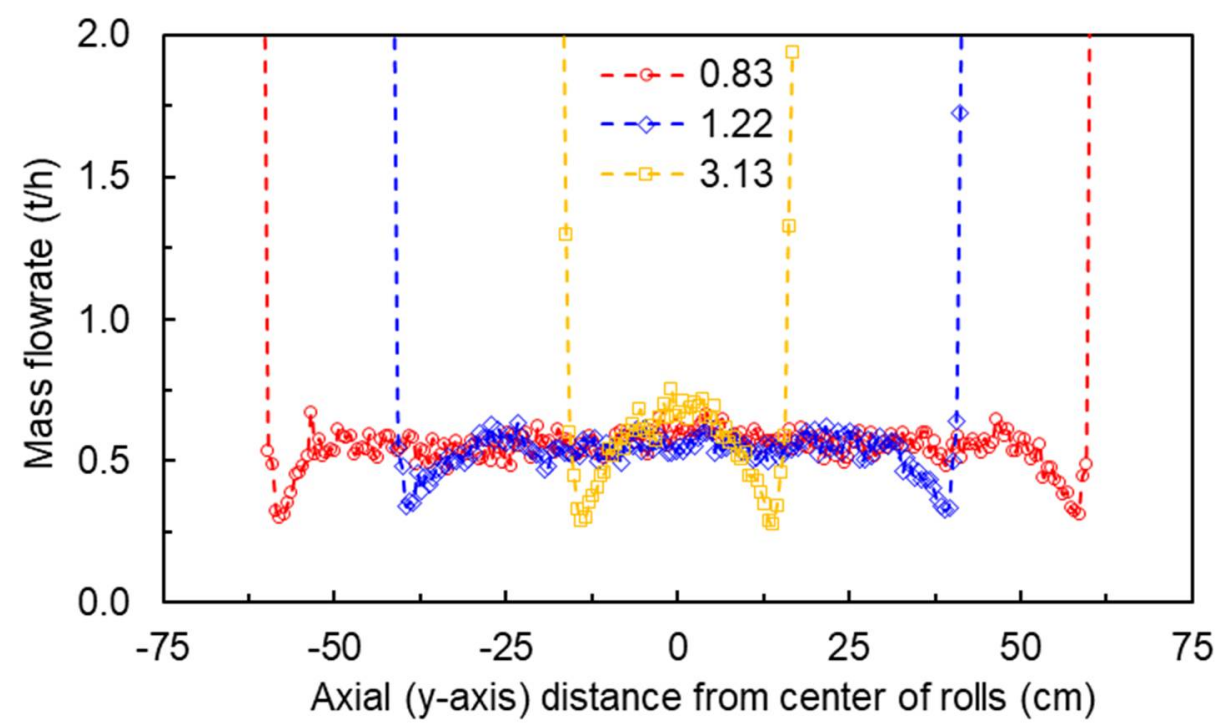

Figure 10. Predicted average axial mass flowrate profiles along the rolls of HPGRs with cheek plates and different aspect ratios, operating at a specific force of $3.5 \mathrm{~N} / \mathrm{mm}^{2}$, rolls velocity of $0.5 \mathrm{~m} / \mathrm{s}$ and bypass clearance of $11 \mathrm{~mm}$.

The force distribution along the rolls is presented in Figure 11. The vertical dotted lines represent the projection of the rolls length, matching the colors of the pressure profile for the HPGRs with each of the aspect ratios studied. It shows that maximum forces in the gap region are similar for the HPGRs with the different aspect ratios simulated. Lower aspect ratios (0.83 and 1.22) evidenced a more homogenous pressure/force profile along the rolls, which may generate a more regular wear pattern than that expected for higher aspect ratios, as suggested by other researchers $[5,8]$. However, the edge effect or drop pressure area is very similar in length for simulated HPGRs with all aspect ratios, since in all the cases it starts to appear at a distance of $11.8 \pm 0.3 \mathrm{~cm}$ from the edge of each roll. As such, the proportion of edge product significantly increases with aspect ratio of the HPGR, which is in agreement with findings reported by Morley [5]. However, in contrast to the reported by the same author [5], a direct relationship between the size of the edge zone and the operating gap was not observed.

On the other hand, some authors have stated that HPGRs with high-aspect ratio exhibit higher pressure peak in the compression zone, so that they could generate finer product in the center of the rolls $[5,8,12]$. Simulation results, presented in Figure 12, confirmed partially this observation, since they showed that HPGRs with lower aspect ratios $(0.83$ and 1.22) exhibit similar generation of fines in the center zone (average of $18.9 \%$ ) with a reduction towards the edges, while in the case of the higher aspect ratio HPGR (3.13) a peak in the center, with an average $23.8 \%$ of product passing $45 \mu \mathrm{m}$, was produced. However, this result seems inconsistent with the force profile presented in Figure 11, which did not show a marked difference for the high-aspect ratio HPGR.

Although nearly no differences were observed in the maximum forces sustained by the particle bed in the gap region for the different aspect ratios (Figure 11), the force profiles were analyzed for a region above it, maintaining the same length of $100 \mathrm{~mm}$ as presented in Figure 4, but this time from 100 to $200 \mathrm{~mm}$ above the rolls gap. Results are shown in Figure 13, which demonstrate that a peak force appears for the HPGR with the higher aspect ratio, but in a position above the gap, which explains, at least partially, the greater fineness of the product generated from the central portion of the rolls in this case (Figure 12). The simulation suggests that HPGRs with higher ratios increase the confinement before reaching the compression zone, potentially with higher nip angles. 


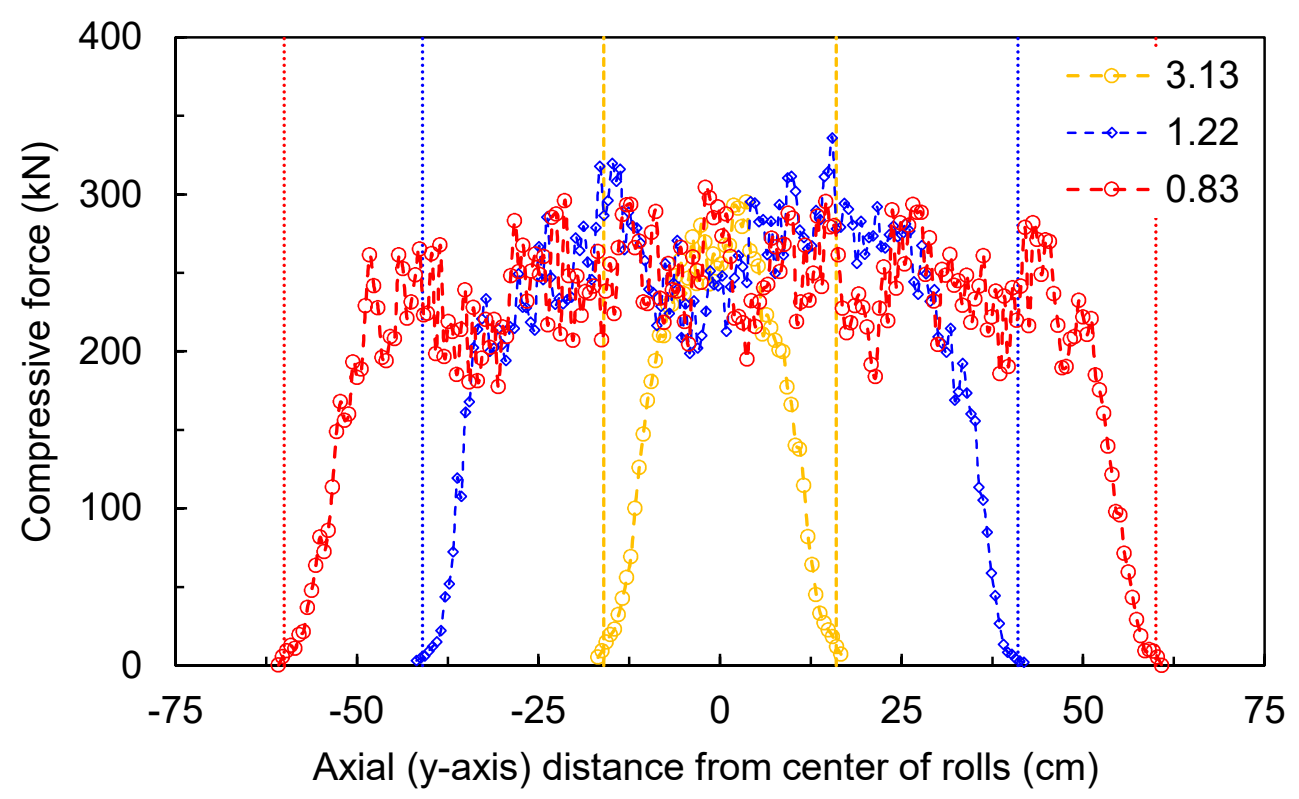

Figure 11. Axial compressive force profiles along the rolls at the gap region for the pilot-scale HPGRs with cheek plates with different aspect (D/L) ratios, operating at a specific force of $3.5 \mathrm{~N} / \mathrm{mm}^{2}$, rolls at a speed of $0.5 \mathrm{~m} / \mathrm{s}$ and bypass gap of $11 \mathrm{~mm}$. Vertical dotted lines identify the projection of the rolls length.

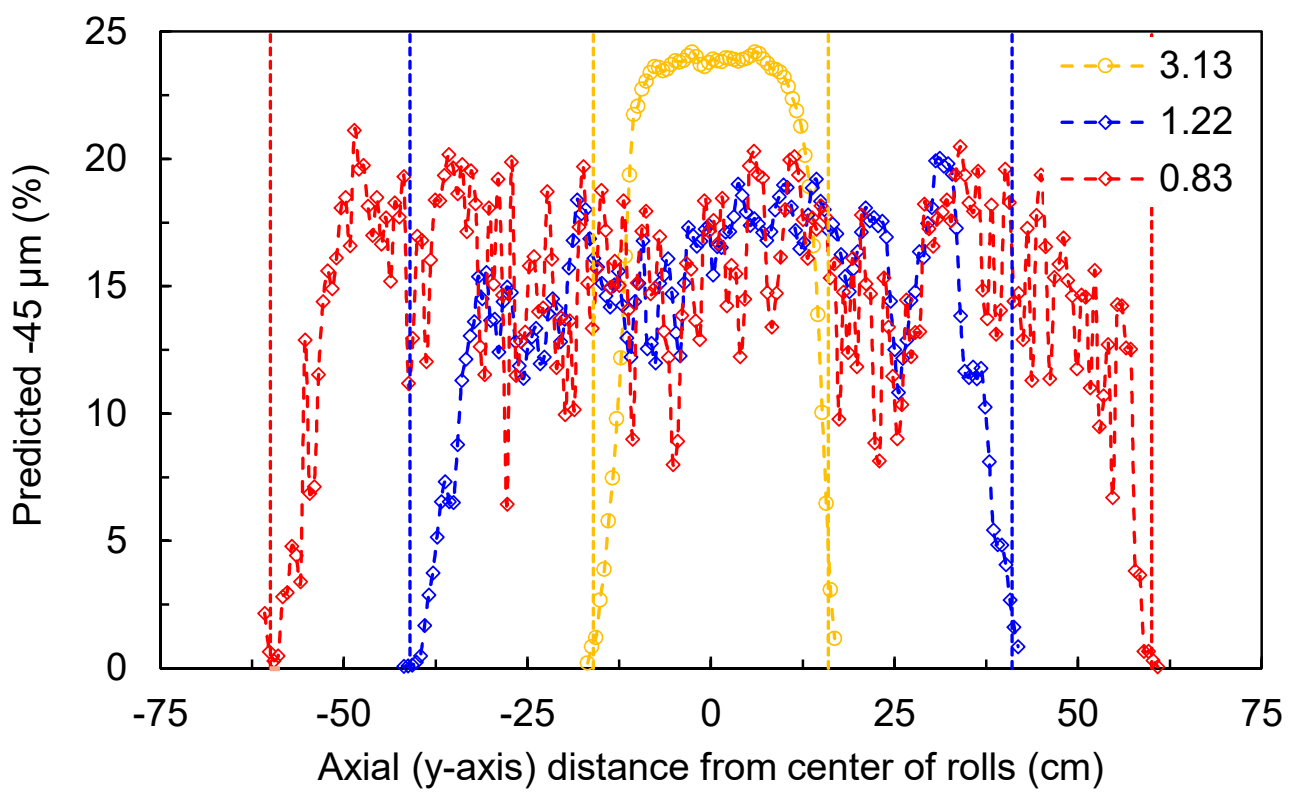

Figure 12. Predicted percentage passing the $45 \mu \mathrm{m}$ sieve in the product for the pilot-scale HPGRs with cheek plates with different aspect (D/L) ratios, operating at a specific force of $3.5 \mathrm{~N} / \mathrm{mm}^{2}$, rolls at a speed of $0.5 \mathrm{~m} / \mathrm{s}$ and cheek plates with bypass gap of $11 \mathrm{~mm}$. Vertical dotted lines identify the projection of the rolls length. 


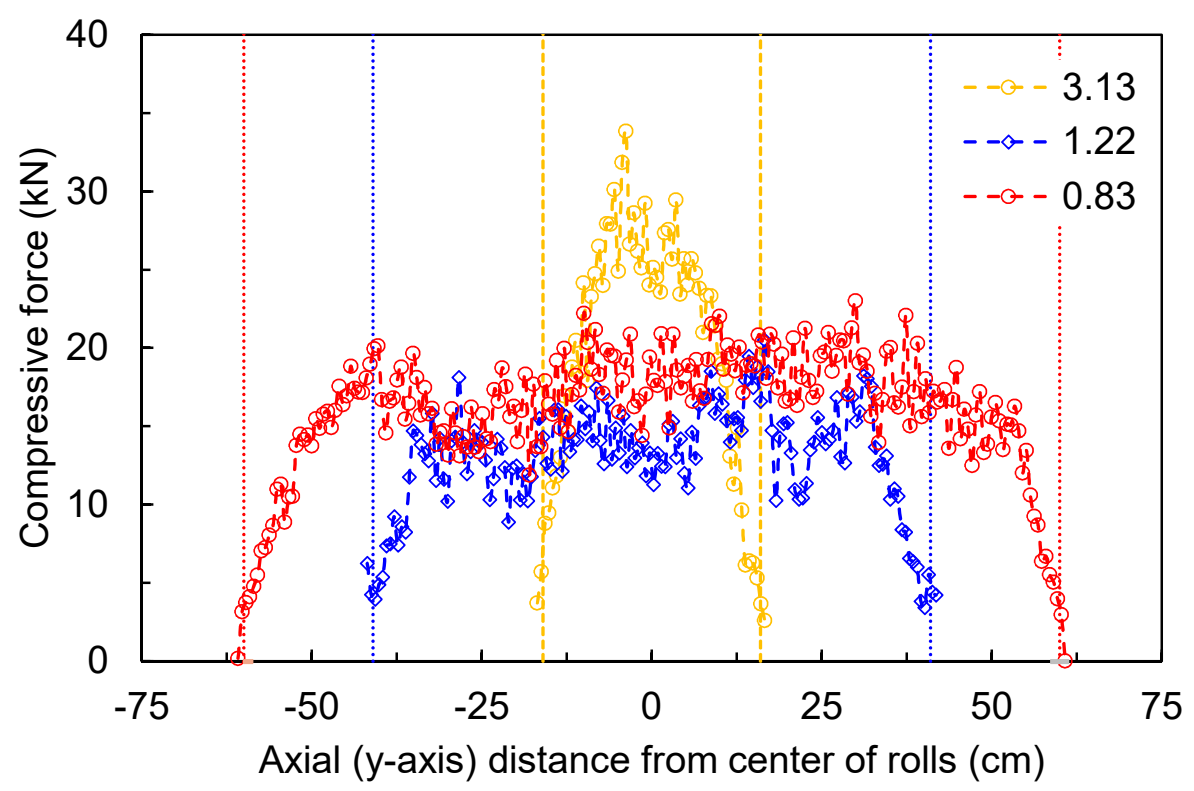

Figure 13. Axial compressive force profiles along the rolls at 10 to $20 \mathrm{~cm}$ above the gap region of the HPGR with cheek plates with different aspect (D/L) ratios, operating at a specific force of $3.5 \mathrm{~N} / \mathrm{mm}^{2}$ and rolls a speed of $0.5 \mathrm{~m} / \mathrm{s}$. Vertical dotted lines identify the projection of the rolls lengths.

\subsection{Roller Wear Condition}

As mentioned in Section 2.6, simulations of the $820 \mathrm{~mm}$ long HPGR rolls (aspect ratio of 1.22) under different roller wear conditions (Figure 2) were performed. Table 8 shows a decrease in the power for the trapezoidal wear profile as a function of the depth of wear, with less energy being applied to the bed of particles between the rolls. This result is consistent with the fineness of the simulated product (percentage $-45 \mu \mathrm{m}$ ), showing a more modest reduction in size for the trapezoidal profile with the most intensive wear (5 mm).

Table 8. HPGR performance variables resulting from simulations of the $820 \mathrm{~mm}$ long roller (aspect ratio of 1.22) under different wear conditions. Simulations of the HPGR operating at a specific force of $3.5 \mathrm{~N} / \mathrm{mm}^{2}$ and rolls velocity of $0.5 \mathrm{~m} / \mathrm{s}$.

\begin{tabular}{|c|c|c|c|c|c|c|}
\hline $\begin{array}{c}\text { Roller Wear } \\
\text { Condition/Wear Depth }\end{array}$ & $\begin{array}{l}\text { Working Gap } \\
(\mathrm{mm})\end{array}$ & $\begin{array}{l}\text { Throughput } \\
(\mathrm{t} / \mathrm{h})\end{array}$ & $\begin{array}{l}\text { Specific Throughput } \\
\left(\mathrm{ts} / \mathrm{hm}^{3}\right)\end{array}$ & Power (kW) & Ecs $(\mathbf{k W h} / \mathrm{t})$ & $\begin{array}{c}\text { Product }-45 \mu \mathrm{m} \\
(\%)\end{array}$ \\
\hline $\mathrm{New} / 0 \mathrm{~mm}$ & 11.7 & 77.3 & 188.5 & 151.6 & 1.96 & 17.5 \\
\hline Parabolic/2.5 mm & 9.8 & 80.4 & 196.1 & 162.2 & 2.02 & 15.2 \\
\hline Trapezoidal $/ 2.5 \mathrm{~mm}$ & 4.7 & 78.8 & 192.2 & 117.0 & 1.49 & 17.1 \\
\hline Trapezoidal $/ 5.0 \mathrm{~mm}$ & 6.7 & 82.6 & 201.5 & 104.7 & 1.27 & 15.6 \\
\hline Trapezoidal/2.5 mm* & 3.8 & 85.0 & 207.4 & 155.2 & 1.82 & 18.3 \\
\hline
\end{tabular}

* Simulation with specific force of $4.0 \mathrm{~N} / \mathrm{mm}^{2}$ and roll tangential velocity of $0.6 \mathrm{~m} / \mathrm{s}$.

At first, Figure 14 shows that the axial compressive force profile for the new roller surface may be interpreted as being more consistent with the trapezoidal wear profile in Figure 2, since it exhibits a significant portion of the central region of the rollers with the bed of particles being subjected to a nearly constant force. The figure then shows that the trapezoidal wear generates a profile known as "bathtub", showing a significant drop in the force in the middle portion. On the other hand, the parabolic wear profile has a more uniform distribution of compressive forces between center and edge regions. 


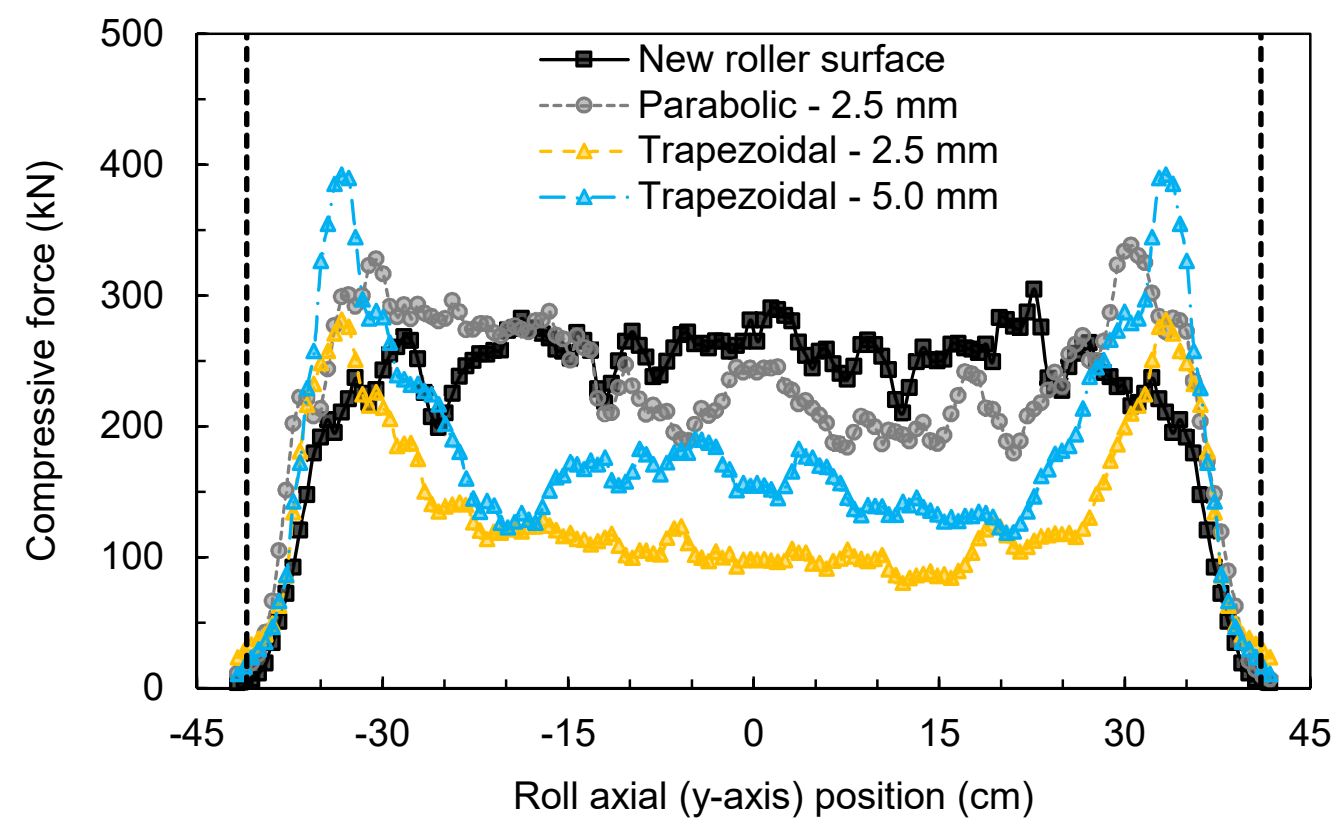

Figure 14. Axial compressive force profiles along the rolls in the gap region for different surface wear conditions operating at specific force of $3.5 \mathrm{~N} / \mathrm{mm}^{2}$ and rolls speed of $0.5 \mathrm{~m} / \mathrm{s}$. Vertical dotted lines identify the projection of the rolls length.

An analysis of the axial throughput profile in Figure 15 shows that higher values are found in the central portion of the rolls, in particular in the case of the more intensive wear $(5 \mathrm{~mm})$ as well as with parabolic wear profile. The actual gap between the rolls (Table 8) does not provide a proper description of the measure since it is varying according to the degree of wear along the rolls, so that for the trapezoidal profile with deepest wear $(5 \mathrm{~mm})$ the gap ends up being reduced using the MBD to compensate for the compressive force.

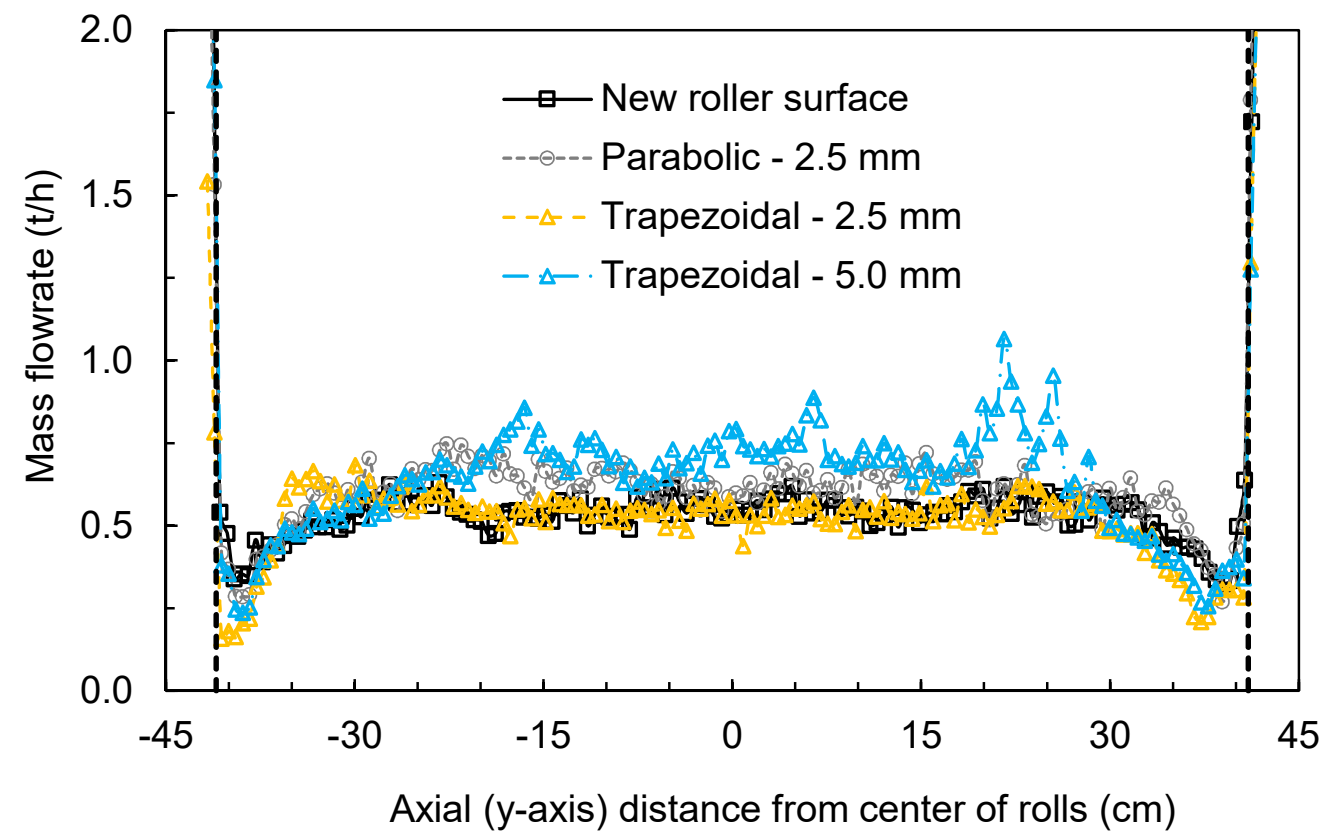

Figure 15. Axial throughput profiles along the rolls for different surface wear conditions for the HPGR operating with cheek plates operating at specific force of $3.5 \mathrm{~N} / \mathrm{mm}^{2}$ and rolls speed of $0.5 \mathrm{~m} / \mathrm{s}$. Vertical dotted lines identify the projection of the rolls length. 
Figure 16 then shows the profile of predicted product percent passing $45 \mu \mathrm{m}$ along the rolls for the different wear conditions simulated. It shows that worn rolls surfaces produce greater heterogeneity in the predicted percent passing $45 \mu \mathrm{m}$ along the rolls, being the trapezoidal profile with the highest wear $(5 \mathrm{~mm})$ the one responsible for the most heterogeneous profile. An apparent inconsistency of the comparatively low magnitude of forces for the case of the trapezoidal wear profile with $2.5 \mathrm{~mm}$ depth in the middle portion of the rolls (Figure 14) and the reasonably high fineness of the product in this portion (Figure 16) has been identified. However, in analogy to Figure 13 for the simulation with the HPGR with the high-aspect ratio, this may be explained by the fact that forces in the region above the gap were found to be higher for this condition in comparison to the others simulated, demonstrating a potential effect of wear on the nip angle, already suggested in the literature [8]. These results are; however, omitted for brevity.

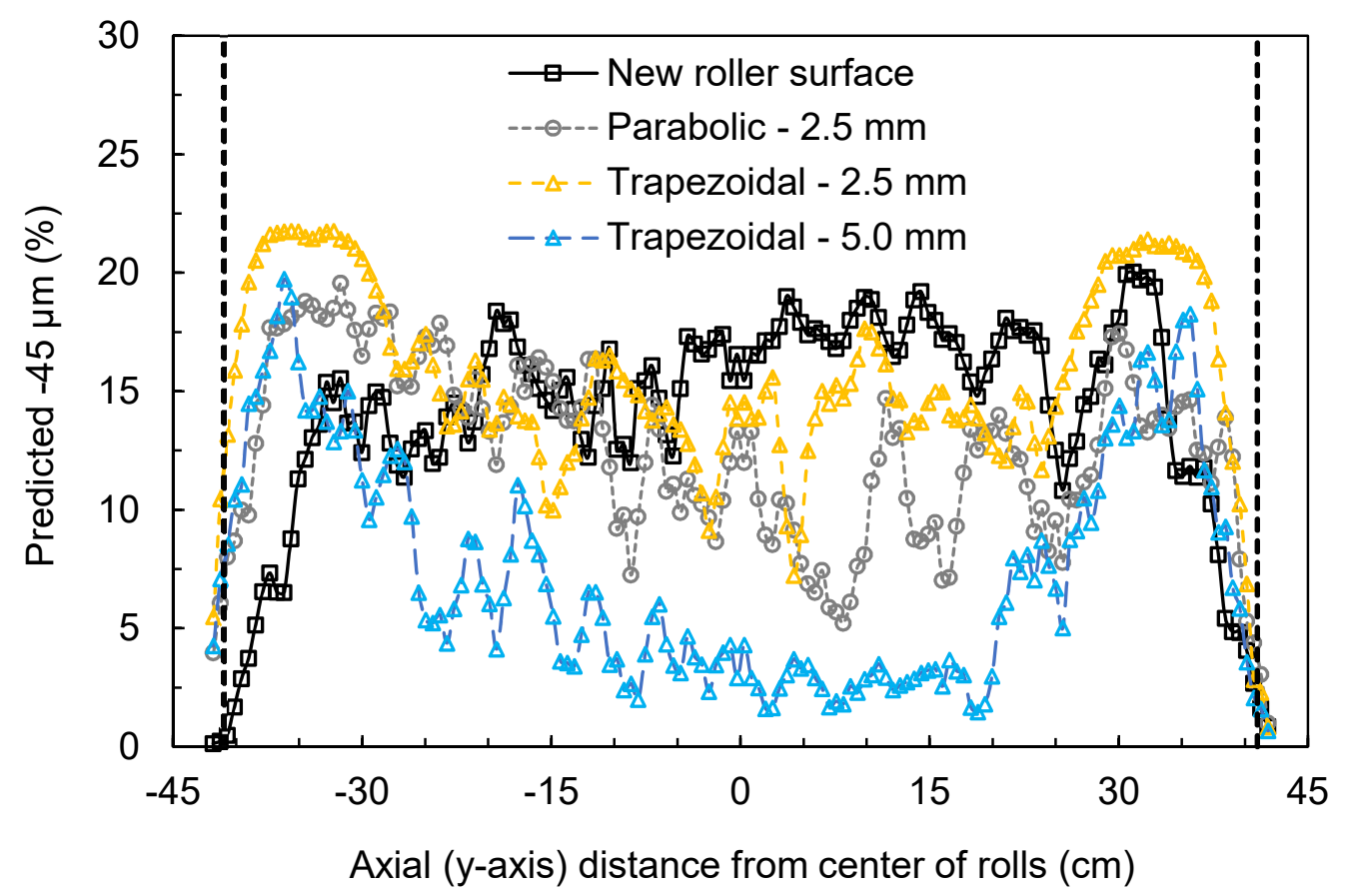

Figure 16. Predicted product percent passing $45 \mu \mathrm{m}$ along the rolls for different surface wear conditions for the HPGR with cheek plates operating at specific force of $3.5 \mathrm{~N} / \mathrm{mm}^{2}$ and rolls speed of $0.5 \mathrm{~m} / \mathrm{s}$. Vertical dotted lines identify the projection of the rolls length.

Power is an important variable used in controlling industrial HPGR operations, as the decrease in power observed as the result of increasing wear has led to a reduction in fineness of the product, as demonstrated in Table 8. A common approach used in industry to circumvent this coarsening of the product with roller wear is to increase the pressure so as to match the power reached with the new roller and, whenever necessary, adjust the roller speed to set throughput back to the level reached with the new roller. As such, an additional simulation for the case of the $2.5 \mathrm{~mm}$ wear following the trapezoidal profile was conducted increasing the specific force to $4.0 \mathrm{~N} / \mathrm{mm}^{2}$ and the roll velocity to $0.6 \mathrm{~m} / \mathrm{s}$ and the summary of the results is also shown in Table 8. It shows that increasing the specific force so as to approximately match the power reached by the HPGR with new rollers results in even an increase in product fineness with the worn rolls surface. That led to an even smaller roller gap, reducing HPGR throughout, which was compensated by increasing rolls velocity, resulting in an even higher throughput (Table 8). Although successful, this approach has the limitation of increasing heterogeneity in the product fineness. In addition, the higher pressures demanded can result in working gaps that may reach the minimum safety gap between the rolls. 


\section{Conclusions}

Simulations using the DEM-MBD-PRM coupling allowed to predict the effect of variations in the confinement system, aspect ratio and rolls wear condition on key operating variables. In addition, in-depth analysis of the HPGR performance was possible through inspections of mass flowrate, compressive force and percentage passing $45 \mu \mathrm{m}$ along the length of the rolls.

Simulations of the different confinement systems demonstrated that HPGRs equipped with flanges allowed reaching higher throughputs when compared to that with cheek plates, confirming reports from the literature. The edge effect was reduced with the use of flanges, more so when flanges were fitted with studs, but that resulted in lower forces acting on the bed of particles in the gap region. The reduction in the edge effect resulted in a more homogeneous product PSD.

Simulations of HPGRs with different aspect ratios with $1000 \mathrm{~mm}$ diameter rolls showed some marked trends. The absolute size of the region in the rolls in which the pressure is reduced (edge region) appears at a mean distance of about $120 \mathrm{~mm}$ from the edge of the rolls, which translates in proportionally larger edge regions for rolls with higher aspect ratios. On the other hand, product fineness increased with aspect ratio, with simulations with the rolls with the highest aspect ratio exhibiting the finest product, in particular in the central region. Such result was explained on the basis of higher forces acting on the bed above the rolls gap, which suggests an increase in nip angle for highaspect ratio HPGRs.

Investigation of the impact of roller wear allowed to demonstrate important effects of different types of profiles and depth of wear on the HPGR performance. It was found that the most common trapezoidal roller profile results in highly heterogeneous force profiles along the rolls, with the bathtub-like profile of both forces and produce fineness towards the central region. Such profile led to a significant reduction in power and product fineness, as commonly observed in plant operation. The strategy used to compensate for this was an increase in specific force, coupled to an increase in roll velocity, so as to match the power demanded by the HPGR when new. This proved to be able to match-and even exceed-both product fineness and throughput but has the limitation of further reducing the working gap, which will quickly reach the minimum safety (zero) gap as it is applied in association to higher wear depths. It is worth mentioning; however, that simulations predicted a less severe reduction in fineness of the product with wear, than is observed in practice, when pressing iron ore pellet feed, which suggests further studies must be conducted to further validate the breakage model in this application.

In spite of its limitation in quantitatively describing the fineness of the product, the simulation approach was demonstrated to be a powerful tool in the design of HPGRs in the future.

Author Contributions: Conceptualization, V.A.R., G.K.P.B. and L.M.T.; methodology, V.A.R., G.K.P.B. and L.M.T.; software, V.A.R., G.K.P.B. and L.M.T.; validation, V.A.R. and G.K.P.B.; formal analysis, V.A.R., G.K.P.B. and L.M.T.; investigation, V.A.R., G.K.P.B., G.B. and L.M.T.; resources, L.M.T.; data curation, V.A.R., G.K.P.B. and G.B.; writing—original draft preparation, V.A.R., G.K.P.B., G.B. and L.M.T.; writing - review and editing, V.A.R., G.K.P.B., G.B. and L.M.T.; funding acquisition, G.B. and L.M.T. All authors have read and agreed to the published version of the manuscript.

Funding: This research was funded by Vale S.A., with partial funding by the Brazilian research agencies CNPq (grant number 310293/2017-0), FAPERJ (grant number E-26/202.574/2019), "Coordenação de Aperfeiçoamento de Pessoal de Nível Superior-Brasil" CAPES (finance Code 001 and grant number-88881.188860/2018-01).

Acknowledgments: The authors would like to thank Vale S.A. for financial and technical support to the research, as well as permission to publish this work.

Conflicts of Interest: The authors declare no conflict of interest. 


\section{References}

1. Ballantyne, G.R.; Hilden, M.; van der Meer, F.P. Improved characterisation of ball milling energy requirements for HPGR products. Miner. Eng. 2018, 116, 72-81. [CrossRef]

2. Morrell, S. Predicting the specific energy required for size reduction of relatively coarse feeds in conventional crushers and high pressure grinding rolls. Miner. Eng. 2010, 23, 151-153. [CrossRef]

3. Ozcan, O.; Aydoğan, N.A.; Benzer, H. Effect of operational parameters and recycling load on the high pressure grinding rolls (HPGR) performance. Int. J. Miner. Process. 2015, 136, 20-25. [CrossRef]

4. Dunne, R.; Maxton, D.; Morrell, S.; Lane, G. HPGR-The Australian Experience. Plant Oper. Forum. $2004,1,153-162$.

5. Morley, C. HPGR-FAQ The users Who uses HPGR? S. Afr. Inst. Min. Metal. 2010, 110, 17-20.

6. Mclvor, R.E. High Pressure Grinding Rolls. A review. In Comminution Practices; Kawatra, S.K., Ed.; SME: Littleton, CO, USA, 1995; pp. 95-98.

7. Mosher, J. Comminution circuits for gold ore processing. Gold Ore Process. 2016, 259-277. [CrossRef]

8. Rashidi, S.; Rajamani, R.K.; Fuerstenau, D.W. A review of the modeling of high pressure grinding rolls. KONA Powder Part. J. 2017, 34, 125-140. [CrossRef]

9. Patzelt, N.; Knecht, J.; Burchardt, E.; Klymowsky, R. Challenges for high pressure grinding in the new millennium. Mill Oper. Conf. 2000, 7, 47-55.

10. Van Der Meer, F.P.; Maphosa, W. High pressure grinding moving ahead in copper, iron, and gold processing. J. S. Afr. Inst. Min. Metal. 2012, 112, 637-647.

11. Herman, V.; Knorr, B.; Whalen, D. HRC: Taking HPGR efficiency to the next level by reducing edge effect. Int. Miner. Proc. Conf. 2013, 1, 195-202.

12. Sönmez, B.; Oliveira, R.; Jankovic, A.; Valery, W.; Us, M. Metso HRC-Energy efficient comminution technology basic principles. Balk. Min. Process. Congr. 2015, 1, 131-138.

13. Maxton, D.; Morley, C.; Bearman, R. A quantification of the benefits of high pressure rolls crushing in an operating environment. Miner. Eng. 2003, 16, 827-838. [CrossRef]

14. Bearman, R. High-pressure grinding rolls-Characterising and defining process performance for engineers. In Advances in Comminution; Kawatra, S.K., Ed.; SME: Littleton, CO, USA, 2006; pp. 3-14.

15. Van der Ende, R.; Knapp, H.; Van der Meer, F. Reducing edge effect and material Bypass using spring-loaded cheek plates in HPGR grinding. Semi-Autogenous Grind. High Press. Grind. Roll Tech. Conf. 2019, 1, 1-9.

16. Saramak, D.; Saramak, A. Potential benefits in copper sulphides liberation through application of HRC device in ore comminution circuits. Minerals 2020, 10, 817. [CrossRef]

17. Van Wyk, G.; Mackert, T.; Burchardt, E. HPGR Pro-Poised to evolve from revolution to disruptive innovation in mineral processing. In Proceedings of the 12th International Comminution Symposium, Cape Town, South Africa, 27-30 April 2020.

18. Lim, W.; Weller, K. Some benefits of using studded surfaces in high pressure grinding rolls. Miner. Eng. 1999, 12, 187-203. [CrossRef]

19. Battersby, M.J.G.; Kellerwessel, H.; Oberheuser, G. High pressure particle bed comminution of ores and minerals-a challenge. Int Min. Proc. Cong. 1993, 1, 1403-1408.

20. Nejad, R.K.; Sam, A. The wear pattern in high pressure grinding rolls. Miner. Process. Extr. Met. 2017, 126, 238-244. [CrossRef]

21. Oliveira, R.; Delboni, H.; Bergerman, M. Performance analysis of the HRC HPGR in pilot plant. Rem Rev. Escola Minas. 2016, 69, 227-232. [CrossRef]

22. Campos, T.M.; Bueno, G.; Barrios, G.K.; Tavares, L. Pressing iron ore concentrate in a pilot-scale HPGR. Part 1: Experimental results. Miner. Eng. 2019, 140, 105875. [CrossRef]

23. Rashidi, S.; Rajamani, R.K. HPGR rolls surface wear: In-line scanning of a laboratory-scale HPGR. Mining, Met. Explor. 2019, 37, 239-249. [CrossRef]

24. Rosario, P.; Hall, R.; Grundy, M.; Klein, B. A preliminary investigation into the feasibility of a novel HPGR-based circuit for hard, weathered ores containing clayish material. Miner. Eng. 2011, 24, 290-302. [CrossRef]

25. Weerasekara, N.S.; Powell, M.S.; Cleary, P.W.; Tavares, L.M.; Evertsson, M.; Morrison, R.D.; Quist, J.; Carvalho, R.M. The contribution of DEM to the science of comminution. Powder Technol. 2013, 248, 3-24. [CrossRef]

26. Barrios, G.K.; Tavares, L. A preliminary model of high pressure roll grinding using the discrete element method and multi-body dynamics coupling. Int. J. Miner. Process. 2016, 156, 32-42. [CrossRef]

27. Herbst, J.A.; Mular, M.A.; Pate, W.T.; Qiu, X. Detailed modeling of an HPGR/HRC for Prediction of Plant Scale Unit Performance. In Proceedings of the SAG2011 Conference, Vancouver, BC, Canada, 25-28 September 2011.

28. Quist, J.; Evertsson, M. Cone crusher modelling and simulation using DEM. Miner. Eng. 2016, 85, 92-105. [CrossRef]

29. Nagata, Y.; Tsunazawa, Y.; Tsukada, K.; Yaguchi, Y.; Ebisu, Y.; Mitsuhashi, K.; Tokoro, C. Effect of the roll stud diameter on the capacity of a high-pressure grinding roll using the discrete element method. Miner. Eng. 2020, 154, 106412. [CrossRef]

30. Cleary, P.W.; Sinnott, M.D. Axial pressure distribution, flow behaviour and breakage within a HPGR investigation using DEM. Miner. Eng. 2021, 163, 106769. [CrossRef]

31. Rodriguez, V.A.; Barrios, G.K.P.; Bueno, G.; Tavares, L.M. Calibration and validation of coupled DEM-MBD-PRM simulations of pilot-scale HPGRs with different lateral confinements. Miner. Eng. 2021, Submitted. 
32. Tavares, L.M.; Rodriguez, V.A.; Souzani, M.; Padros, C.B.; Ooi, J.Y. An effective sphere-based breakage model for simulation in DEM. Powder Technol. 2021, 392, 473-488. [CrossRef]

33. Cundall, P.A.; Strack, O.D.L. A discrete numerical model for granular assemblies. Géotechnique 1979, 29, 47-65. [CrossRef]

34. Tavares, L.M.; Das Chagas, A.S. A stochastic particle replacement strategy for simulating breakage in DEM. Powder Technol. 2021, 377, 222-232. [CrossRef]

35. Edwards, W.; Pérez-Prim, J.; Barrios, G.K.P.; Tavares, L.M.; Edward, D.; Santhanam, P. A coupling interface for co-simulation of EDEM with multi-body dynamics. Int. Conf. Discr. Elem. Meth. 2013, 1, 361-366.

36. Campos, T.M.; Bueno, G.; Tavares, L.M. Modeling comminution of iron ore concentrates in industrial-scale HPGR. Powder Technol. 2021, 383, 244-255. [CrossRef]

37. Campos, T.M.; Bueno, G.; Barrios, G.; Tavares, L. Pressing iron ore concentrate in a pilot-scale HPGR. Part 2: Modeling and simulation. Miner. Eng. 2019, 140, 105876. [CrossRef]

38. Daniel, M.; Morrell, S. HPGR model verification and scale-up. Miner. Eng. 2004, 17, 1149-1161. [CrossRef]

39. Torres, M.; Casali, A. A novel approach for the modelling of high-pressure grinding rolls. Miner. Eng. 2009, 22, 1137-1146. [CrossRef]

40. Quist, J.; Evertsson, M. Simulating pressure distribution in HPGR using the discrete element method. Int. Comminution Symp. 2012, 1, 1-14. 